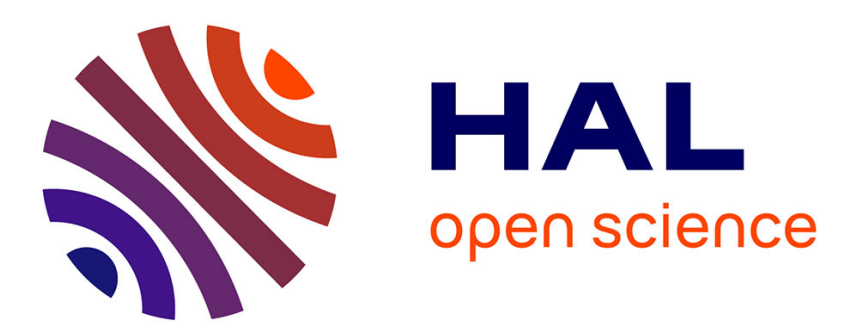

\title{
Bioinspired Energy Harvesting from Atmospheric Phenomena for Small Unmanned Aerial Vehicles
}

Nikola Gavrilović, Murat Bronz, Jean-Marc Moschetta

\section{To cite this version:}

Nikola Gavrilović, Murat Bronz, Jean-Marc Moschetta. Bioinspired Energy Harvesting from Atmospheric Phenomena for Small Unmanned Aerial Vehicles. Journal of Guidance, Control, and Dynamics, 2020, 43 (4), pp.685-699. 10.2514/1.G004730 . hal-02917043

\section{HAL Id: hal-02917043 \\ https://hal-enac.archives-ouvertes.fr/hal-02917043}

Submitted on 18 Aug 2020

HAL is a multi-disciplinary open access archive for the deposit and dissemination of scientific research documents, whether they are published or not. The documents may come from teaching and research institutions in France or abroad, or from public or private research centers.
L'archive ouverte pluridisciplinaire HAL, est destinée au dépôt et à la diffusion de documents scientifiques de niveau recherche, publiés ou non, émanant des établissements d'enseignement et de recherche français ou étrangers, des laboratoires publics ou privés. 


\title{
Bioinspired Energy Harvesting from Atmospheric Phenomena for Small Unmanned Aerial Vehicles
}

\author{
Nikola Gavrilović,,$*$ Murat Bronz,, \pm and Jean-Marc Moschetta \\ University of Toulouse, 31400 Toulouse, France \\ https://doi.org/10.2514/1.G004730
}

\begin{abstract}
This Paper discusses energy harvesting from atmospheric phenomena for small unmanned aerial vehicles, theoretically through simulations and practically through experimental flights. A comparison between different scenarios for flight within the sinusoidal wind profile is presented. A significant improvement in performance with active control of command surfaces has been found for an energy-harvesting mode when compared to autostabilization or fixed-stick flight. Moreover, a detailed decomposition of the stochastic wind profile generated from the Kaimal spectrum has shown which frequencies and magnitudes of wind time series have the highest contribution to the energy-transfer process. It is found that wind profiles with higher turbulence intensity potentially provide more energy for transfer to the aircraft. Furthermore, the Paper reveals a biologically inspired sensory system for wind field estimation. It describes the necessary equipment and control algorithms for the exploitation of atmospheric energy. Initial flight tests were performed to determine the average power consumption of the motor for altitude hold tasks and to evaluate the performance of sensors. Moreover, additional flights for autonomous exploitation of several atmospheric phenomena are presented and analyzed.
\end{abstract}

$A, B$
$C_{D}$
$C_{L}$
$C_{T}$
$C_{0}, \ldots, C_{n}$
$c$
$D$
$E$
$F_{\alpha}$
$K_{1}, \ldots, K_{n}$
$k_{g}$
$k_{w}$
$L$
$M$
$m$
$P$
$p$
$q$
$S$
$T$
$T_{i}$
$t$
$V$
$W$
$w_{x}, w_{z}$
$X$
$Y$
$Z$
$\alpha$

\section{Nomenclature}

adjustable constants

drag coefficient

lift coefficient

thrust coefficient

constant gains

mean aerodynamic cord, $\mathrm{m}$

drag force, $\mathrm{N}$

specific energy, $\mathrm{J} / \mathrm{kg}$

low-frequency spectrum

control gains

sinusoidal gust amplitude, $\mathrm{m} / \mathrm{s}$

wave number

lift force, $\mathrm{N}$

moment, $\mathrm{Nm}$

mass, $\mathrm{kg}$

specific power, $\mathrm{J} \cdot \mathrm{kg}^{-1} \cdot \mathrm{s}^{-1}$

pressure, $\mathrm{Pa}$

dynamic pressure, $\mathrm{Pa}$

wing surface, $\mathrm{m}^{2}$

thrust force, $\mathrm{N}$

turbulence intensity

time, $\mathrm{s}$

airspeed, $\mathrm{m} / \mathrm{s}$

weight, $\mathrm{N}$

- longitudinal and vertical components, $\mathrm{m} / \mathrm{s}$

vehicle horizontal position, $\mathrm{m}$

vehicle lateral position, $\mathrm{m}$

vehicle vertical position, $\mathrm{m}$

angle of attack, deg
*Postdoctoral Researcher, ISAE-SUPAERO, Department of Aerodynamics, Energetics and Propulsion, 10 Avenue Edouard-Belin BP 54032. Member AIAA.

${ }^{\dagger}$ Assistant Professor, ENAC, Applied Aerodynamics URI-Drones, 7 Avenue Edouard-Belin BP 54032. Member AIAA.

${ }^{\ddagger}$ Full Professor, ISAE-SUPAERO, Department of Aerodynamics, Energetics and Propulsion, 10 Avenue Edouard-Belin BP 54032. Member AIAA.

$\begin{array}{lll}\gamma & = & \text { flight-path angle, deg } \\ \delta & = & \text { control activation angle, deg } \\ \theta & = & \text { pitch angle, deg } \\ \sigma & = & \text { intensity of fluctuations } \\ \phi & = & \text { roll angle, deg } \\ \psi & = & \text { yaw angle, deg }\end{array}$

\section{Subscripts}

$\begin{array}{ll}a & =\text { air-mass referenced } \\ c & =\text { command } \\ e & =\text { elevator or both ailerons } \\ i & =\text { vector/component expressed in inertial frame } \\ m & =\text { spectral peak }\end{array}$

\section{Introduction}

S MALL unmanned aerial vehicles (SUAVs) usually fly in lower levels of the atmospheric boundary layer. Such a flight is often exposed to a turbulent environment provoked by complex meteorological conditions. Those disturbances are usually due to the intricate interaction of the moving atmosphere and Earth's relief and natural world. SUAVs very often fly in the environment very close to birds. It is well known that birds use various flight strategies to exploit atmospheric conditions. Therefore, inspiration can be found and translated into the flight strategy of small robots. The flying speed of birds and SUAVs is on the order of magnitude of the wind speeds that can be encountered in their flying environment. Therefore, such a flying environment provides a sufficient amount of energy that can potentially be harvested. The average magnitude of wind in Europe measured in the horizontal plane at $10 \mathrm{~m}$ above ground followed over a period of 44 years (1957-2002) shows a variation of 2-4 m/s depending on the exact location of the region as presented by Peter [1], while the speed of flight for small unmanned aerial vehicles is usually between 10 and $15 \mathrm{~m} / \mathrm{s}$. The performance in the form of endurance and range for unmanned vehicles grows significantly with their size and mass. The same trend is valid for airspeed. Moreover, SUAVs are usually able to fly with the use of only chemical energy of batteries, with the endurance of up to $1 \mathrm{~h}$ or a couple of hours for very efficient aircraft. An option for considerable improvement in endurance could be achieved with solar cells. However, according to the angle of the panel with the sun rays, time of the day and year, and geographic location, solar cells will have different output power. Therefore, the exploitation of atmospheric energy represents a great opportunity for the performance improvement of SUAVs. 
The work of Phillips [2] has shown that the effect of thrust in the case of the vertical gust is too small to be used on high-speed flying vehicles. On the contrary, this approach has shown that there is a potential for performance improvement of SUAVs. The thrust effect in the case of vertical sinusoidal gust has been also explained by Patel and Kroo [3]. While penetrating the negative vertical wind component (updraft), the aircraft's lift vector tilts forward due to the appearance of the induced angle of attack. Because of the lift force tilting, a new small component of force appears in the forward direction. That force performs a positive work on the aircraft and can be even enlarged if the aircraft performs additional pitching maneuvers. The same principle remains valid for downdraft, in which the aircraft has to experience negative g's. An extensive amount of work has been also reported on the subject of static soaring. This flight technique aims at exploiting a quasi-stationary lifting air mass also known as thermal. One of the most famous strategies defining the necessary speed to fly is known as MacCready [4] theory. An algorithm that could exploit naturally occurring convective thermal updrafts for extending the endurance of unmanned aerial vehicles has been developed recently by Edwards [5] and applied to $4.3 \mathrm{~m}$ wing-span glider. An application of a biomimetic energy-harvesting algorithm to the trajectory planning of a SUAV within atmospheric convection is presented by Gudmundsson et al. [6]. This work is further developed into a control algorithm with a decisive mechanism for whether to deviate from the original flight trajectory or to take advantage of it [7]. The optimal flight trajectories for energy harvesting inspired by albatross flight (that are often called dynamic soaring) were demonstrated by Zhao [8], Bonnin [9], and most recently Liu et al. [10]. While a significant amount of work has been done on exploiting longduration atmospheric effects with a flight strategy often called autonomous soaring (for example, the experiment described by Fisher et al. [11], Watkins et al. [12], Mohamed et al. [13] and most recently by Depenbusch et al. $[14, \overline{15}]$ ) and dynamic soaring (exploiting spatial gradients), a few theoretical works on exploiting gusts have been performed.

Exceptionally complicated urban spaces pose a challenge for the autonomous operation of unmanned aerial vehicles (UAVs). In the urban environment, the characteristic scale is on the order of a few meters, which is due to complex interactions between buildings, trees, and the living world. A simulation tool that captures unsteady aerodynamics of flight through such complex terrain has been presented and demonstrated by Cybyk et al. [16]. All strategies previously described omit advance knowledge or prediction of the wind velocity field ahead of an UAV. However, a method for sensing flow disturbances in the proximity of mini-UAVs and using the output signal for further stabilization has been demonstrated by Mohamed et al. [17-19]. The control strategy has been developed for the roll axis as most sensitive to wind turbulence. Recent experiments by Watkins et al. [20] related to measurements of wind vector components on several spanwise locations confirmed statements about spatial variation of turbulence magnitude. A flush air data system intended for wind vector sensing in dynamic soaring UAVs is presented by Quindlen and Langelaan [21]. The system uses pressure holes on the aircraft nose cone as inspired by wandering albatross and giant petrel nostrils. An overall view of biologically inspired soaring techniques and aerodynamic structures is illustrated by Rasuo [22]. An overview of aerodynamic structures for aircraft drag reduction inspired by wing tips of some natural flyers has been investigated by Gavrilovic et al. [23].

The presented research provides an overall methodology for preparing the system for estimation and exploitation of atmospheric turbulence. Some theoretical aspects, revealing different flight scenarios within the sinusoidal profile, are exposed in Sec. II. A more detailed study for the theoretical investigation of the stochastic wind profile is revealed in Sec. III. Section IV describes the way of feeling the turbulence, inspired by natural flyers and equipment onboard the aircraft. Moreover, it describes the software and its control laws used during experiments. Finally, Sec. $\underline{V}$ reveals the analysis of energy-harvesting flight tests performed at various meteorological conditions.

\section{Flight Simulations Through Sinusoidal Wind Profile}

The flight simulations in this section consider the longitudinal motion of the aircraft represented as a point mass model. The work is an extension of the published papers by Gavrilovic et al. [24,25], in which theoretical analysis of the energy-harvesting technique was demonstrated with both sinusoidal and stochastic wind profiles. This Paper aims at providing quantified benefits through different flight scenarios within the gust environment. The equations of motion are based on the mathematical model presented by Rasuo and Stojakovic $[26,27]$. It is also important to note that aircraft kinetic energy is defined with respect to airspeed rather than groundspeed. While it is possible to use both formulations to solve for flight trajectories, the mechanism by which useful energy is gained must be understood in relation to the vehicle's movement relative to the air. The previous statement is in accord with a description of the energy-harvesting mechanism by Rayleigh [28] and more recently by Taylor et al. [29] and Koessler [30].

The flight mechanics has been solved using Runge-Kutta ordinary differential solver ODE45 found in MATLAB $®$. Aerodynamic coefficients and models used in this section are detailed in Appendix A and are obtained using a modified version of the vortex lattice method (Athena Vortex Lattice program), including the prediction of viscous drag by Bronz [31]. The system of equations describing aircraft motion based on longitudinal dynamics shown in Fig. 1 is the following:

$$
\begin{gathered}
-L+W \cos \gamma=\frac{W}{g}\left(-V \dot{\gamma}+\dot{w}_{x} \sin \gamma+\dot{w}_{z} \cos \gamma\right) \\
T \cos \alpha-D-W \sin \gamma=\frac{W}{g}\left(\dot{V}+\dot{w}_{x} \cos \gamma-\dot{w}_{z} \sin \gamma\right) \\
M=q S c C_{M}=\ddot{\theta} I_{y y}
\end{gathered}
$$

The analysis began with an arbitrarily chosen frequency and amplitude of a sinusoidal gust profile. The objective was to determine and quantify potential benefits from several case scenarios. The first flight was performed in a calm atmosphere (i.e., no wind conditions and calm atmosphere) in which the necessary thrust coefficient was determined in order to perform altitude hold flight. The second flight implied an imposed wind profile in the form of a sinusoidal function. It illustrates the potential benefits in the case of no control (pilot holding the control stick and flying through a predefined sinusoidal gust) as shown in Table 1 . The third flight assumed the use of a proportional-integral regulator for maintaining zero mean altitude hold within given wind conditions. The flight requires $7 \%$ more power when compared to the reference flight. Finally, the fourth flight brought a savings in invested power of around $40 \%$ when compared to a reference value. The flight of energy harvesting within the sinusoidal wind profile implies the use of optimized active control of command surfaces for specific power maximization as

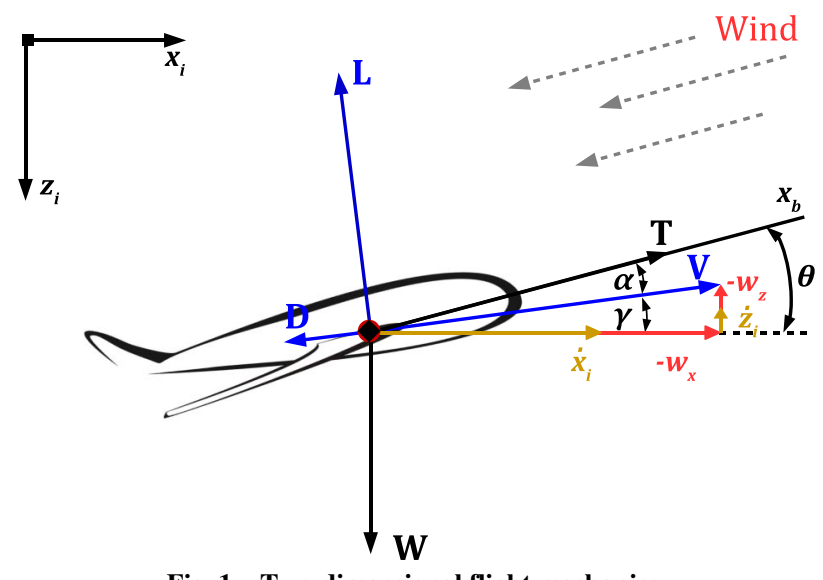

Fig. 1 Two-dimensional flight mechanics. 
Table 1 Flight regime comparison

\begin{tabular}{lll}
\hline \hline Flight case & Altitude hold & Mean energy gain \\
\hline Flight through calm atmosphere & $\pm 0 \mathrm{~m}$ & Reference $C_{T}$ \\
Fixed-stick flight $w_{z}=2 \sin (1.8 t)$ & $\pm 0.4 \mathrm{~m}$ & $+3 \%$ \\
Autostabilization flight $w_{z}=2 \sin (1.8 t)$ & $\pm 0.038 \mathrm{~m}$ & $-6 \%$ \\
Energy harvesting $w_{z}=2 \sin (1.8 t)$ & $\pm 4.2 \mathrm{~m}$ & $+42 \%$ \\
\hline \hline
\end{tabular}

demonstrated by Gavrilovic et al. [24] and Langelaan [32,33]. The optimization of constant gains $K_{1}$ and $K_{2}$ from Eq. (4) for aircraft power maximization was performed with a method explained in the work by Gavrilovic et al. using the genetic algorithm NSGAII found in the OpenMDAO package of PYTHON. The control law (i.e., command surface deflection) is in the form of constant gains multiplying an a priori known wind component and its derivative as shown in Eq. (4). Despite the fact that the genetic algorithm brings the highest energy-harvesting result, the computation time is relatively high. This was important due to the fact that constant coefficients $K_{1}$ and $K_{2}$ had to be optimized for each frequency and magnitude of the sinusoidal wind profile, whereas for the case of flight through the stochastic wind, gain coefficients were obtained for specific profiles. The logic behind chosen control is that the aircraft can pitch up or down depending on the wind profile itself or its derivative,

$$
\delta_{e}=K_{1} w_{x \mid z}+K_{2} \dot{w}_{x \mid z}
$$

The amount of energy gained from wind fluctuations has been compensated with less required thrust to maintain the same mean energy level as in steady flight. Figure 2 shows the last two flight cases from Table 1. Full lines on Fig. 2 represent the energy-harvesting mode. The second subgraph of the figure shows certain parts of specific power. In the case of the energy-harvesting mode, the power coming from wind fluctuations is always positive and of significant magnitude compared to the required power. Figure 2 only shows the last $20 \mathrm{~s}$ of simulation time, as the experienced wind profile and corresponding maneuver (i.e., elevator deflection) and energy state are easier to visualize. To maximize the power coming from wind fluctuations, the aircraft is performing a pitching-up maneuver according to the negative vertical wind and pitching-down maneuver during the positive vertical wind. The wind specific power shown on the second subgraph of Fig. $\underline{2}$ represents the third part of specific power,

$P=\frac{\dot{E}_{a}}{m}=-g w_{z}+\frac{q S}{m}\left(C_{T} \cos \alpha-C_{D}\right) V-V\left(\dot{w}_{x} \cos \gamma-\dot{w}_{z} \sin \gamma\right)$

The last subgraph illustrates the activation of ailerons (for pitching up/down) during the flight, satisfying the constraint of never exceeding 50 deg angle of deflection. Despite the idealistic flow conditions (i.e., unrealistic gust profile), the simulations proved the feasibility of the atmospheric energy-harvesting flight strategy and showed promising values in terms of the extended range and endurance. It can be concluded that energy harvesting brought significant energy savings and would therefore be the preferred flight regime in such atmospheric conditions.

As presented in Table 1, we have used only one arbitrarily chosen frequency and magnitude of the sinusoidal wind profile. To extend the analysis, the following results demonstrate the maximization of specific power (optimal control for each wind profile) for flight within various sinusoidal profiles. The new parameter for quantification of benefits has been introduced as a ratio between specific power from wind fluctuations [i.e., third part of Eq. (5)] and required specific power (drag) for each flight scenario. Any ratio bigger than zero would provide savings in terms of the thrust required to overcome drag. It can be concluded from the results shown in Fig. 3 that the ratio of mean specific power from wind fluctuations and required power grows considerably with the magnitude of the sinusoidal gust. On the contrary, the rise in frequency for a single magnitude did not bring any significant benefits to the overall power of the aircraft.
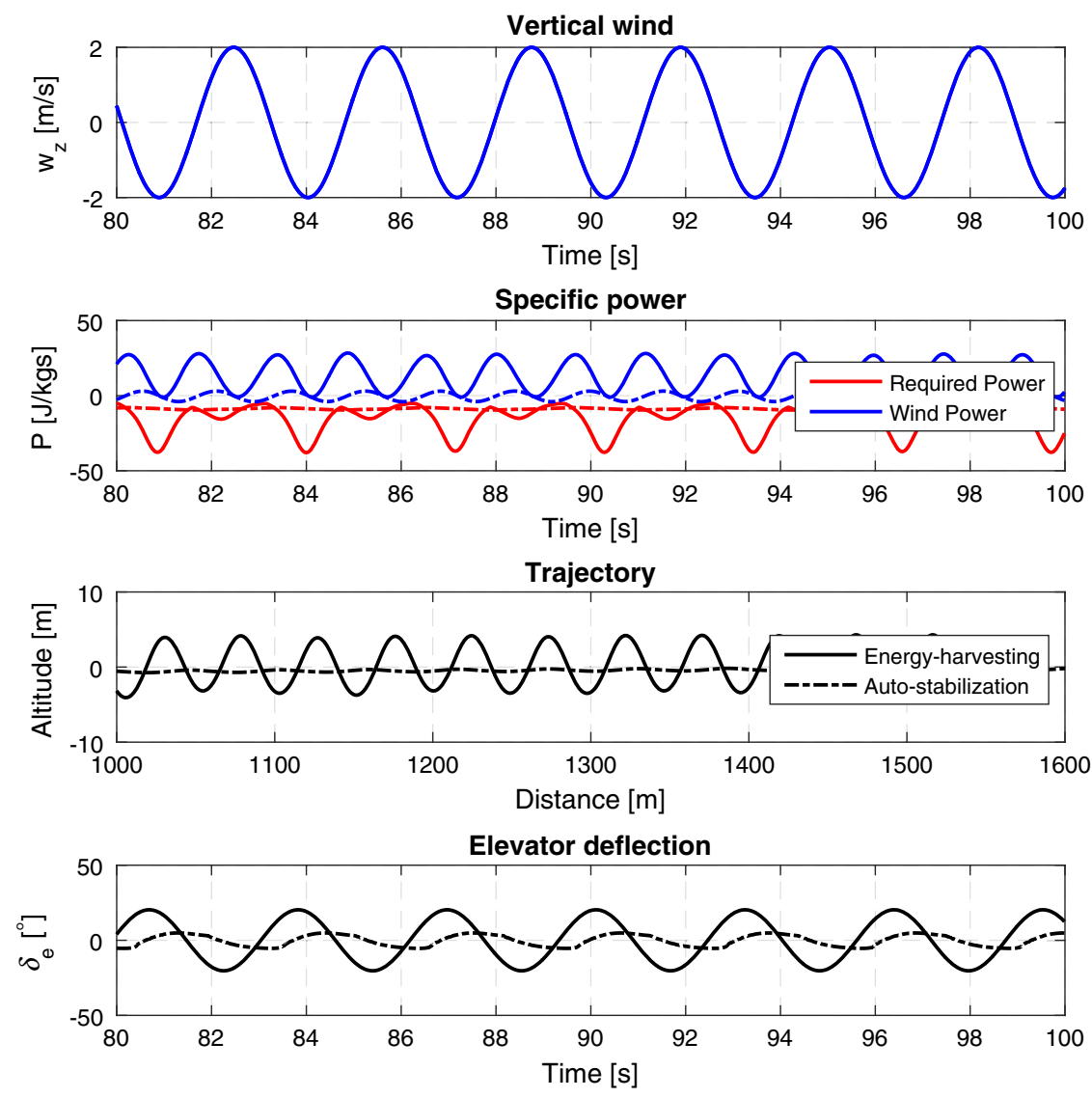

Fig. 2 Flight simulations through sinusoidal gust profile. 


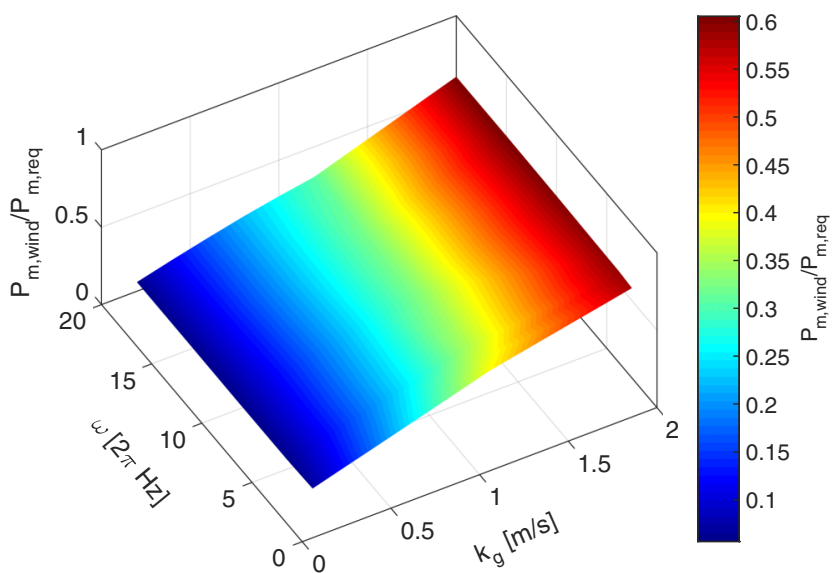

Fig. 3 Ratio of mean specific power from wind fluctuations and required power for sinusoidal profile $w_{z}=k_{g} \sin (\omega t)$.

The results demonstrate the importance and contribution of wind magnitude in the energy transfer between the aircraft and the turbulent atmosphere.

\section{Simulations for Stochastic Wind}

The aim of this section is to explore the benefits of energy harvesting within a stochastic wind profile. The wind time series was built using Kaimal and Finnigan's [34] spectra. Widely used Dryden and von Kármán spectral representations describe an average of all conditions for clear air turbulence. These representations are often used for describing flight conditions that correspond to a commercial aircraft environment. The limitations for those two models are due to the factors not incorporated into the spectral representation, such as terrain roughness, wind shear, and mean wind magnitude. On the contrary, Kaimal and Finnigan's spectra were developed on measurements over flat homogeneous terrain, at the lowest levels of the atmospheric boundary layer. The spectrum used in this analysis is presented in Eq. (6):

$$
F_{\alpha}=\frac{A \sigma_{u}^{2} / k_{w m}}{1+B\left(k_{w} / k_{w m}\right)^{5 / 3}}
$$

The wind profiles used in the analysis were generated with two different values of turbulent intensity $T_{i}=5$ and $15 \%$ as shown in Fig. 4. The chosen length scale was $340 \mathrm{~m}$ for both profiles. The law of turbulence energy dissipation shown in Fig. 4 served as an input for the wind generator. Spectral analysis of generated wind and corresponding time series are presented in Fig. 5. This graph also reveals the number of modes used to generate a single profile. The subgraphs

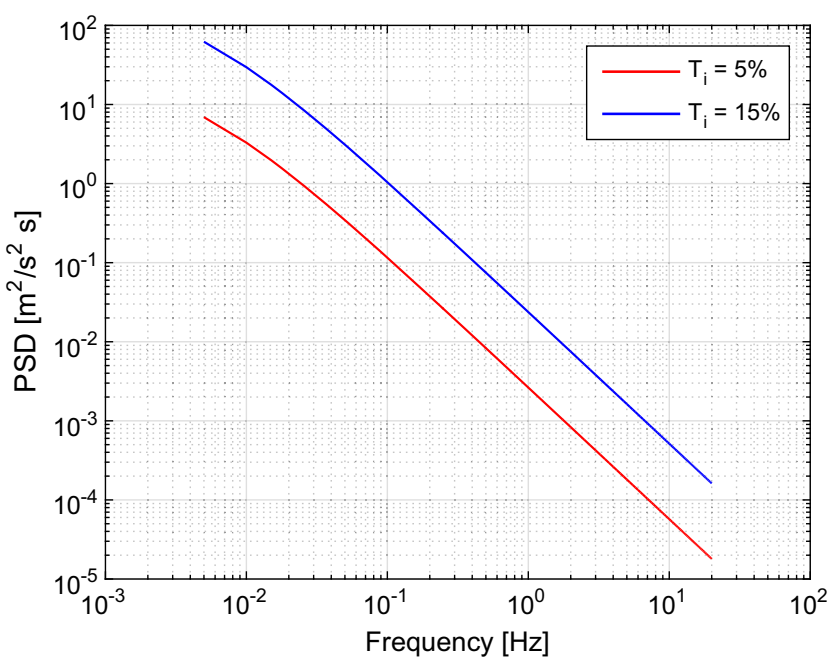

Fig. 4 Power spectral density for turbulence intensities 5 and $15 \%$. of Figs. $5 \mathrm{c}$ and $\underline{5 d}$ show the evolution of the time series of generated wind with a number of modes used for construction. More simply, the wind profiles are made as a sum of sine functions as shown in Eq. (7) with amplitude and frequency shown in Figs. $\underline{5 a}$ and $\underline{5 b}$ :

$$
w_{z, i}=\sum_{i=1}^{n=\text { modes }} M_{a, i} \sin \left(f_{i} t\right)
$$

To avoid the influence of vertical wind itself [the first part in Eq. (5)], wind profiles were constructed so that the mean value of each wind time series is zero. As for simulations in Sec. II, the increase in the energy state will be evaluated through wind specific power [the third part of Eq. (5) for general specific power in longitudinal flight], described by

$$
P_{\dot{w}}=V\left(\dot{w}_{z} \sin \gamma-\dot{w}_{x} \cos \gamma\right)
$$

The objective of energy harvesting is to keep Eq. (ㅁ) positive and maximum with respect to the power required by the changing flight-path angle according to the wind derivative. The first assumption of this analysis is that there is no horizontal wind. Therefore, the change in the flight-path angle will be proportional to the wind derivative. The gain $k_{g}$ from Eq. (9) was chosen with the condition that the flight-path angle never exceeds $50 \mathrm{deg}$. The second assumption in this analysis is related to the flight-path angle, and it claims that the aircraft is capable of following the given law for gamma, no matter the frequency of oscillations. In this way, we avoid the potential study of aircraft maneuverability. In two-dimensional flight dynamics from Sec. II, Eq. (3) describes the necessary moment needed for a certain acceleration in pitch. The most influential parameters here are the inertia of the aircraft and pitching moment coefficient $C_{M \alpha}$. The third assumption is that the unsteady aerodynamic effects are neglected. This involves a highly possible shift in both the frequency and magnitude of lift generated during highfrequency oscillations,

$$
\gamma=k_{g} \dot{w}_{z}
$$

Nevertheless, the study aims at discovering which frequencies and magnitudes of the realistic wind contribute potentially more to an increase in the energy state of the aircraft. Finally, the results are presented in Fig. 6. An increase in the energy state has been quantified through mean specific power for $100 \mathrm{~s}$ of simulation. It can be seen from the graph that the lowest amount of power is obtained for wind profiles made from first modes characterized by a low frequency and high magnitude. As the number of modes for developed wind grows, the increase in mean power becomes more considerable. It means that the aircraft would potentially extract more energy from a more energetic wind profile. Moreover, the rise in the turbulence intensity of the wind increases the efficiency of the energy transfer. The rise from higher turbulence intensity is due to the higher magnitude of wind fluctuations. The results also show that the addition of modes after $2.5 \mathrm{~Hz}$ does not significantly affect the power from wind fluctuations. This is due to the low magnitude of sines that come in addition.

Moreover, two flight simulations were performed within the presented profiles from Fig. 5. As a result, it can be seen from Fig. 7 that the more energetic profile (with $T_{i}=15 \%$ ) indeed brought more positive specific power for the flight of $100 \mathrm{~s}$. These simulations involve Eq. (3), which describes the maneuvering capabilities of the aircraft with mainly its pitching moment coefficient and moment of inertia. This result proves that the aircraft is theoretically capable of performing necessary maneuvers for the maximization of the energy transfer with the turbulent atmosphere that can potentially be experienced in nature. However, the amount of mean power extracted from wind fluctuations from both stochastic profiles with $T_{i}=5$ and $15 \%$ is relatively small when compared to the mean power required for flight. Therefore, the experimental campaign will be targeting large-scale atmospheric phenomena as updrafts and strong wind gradients. 


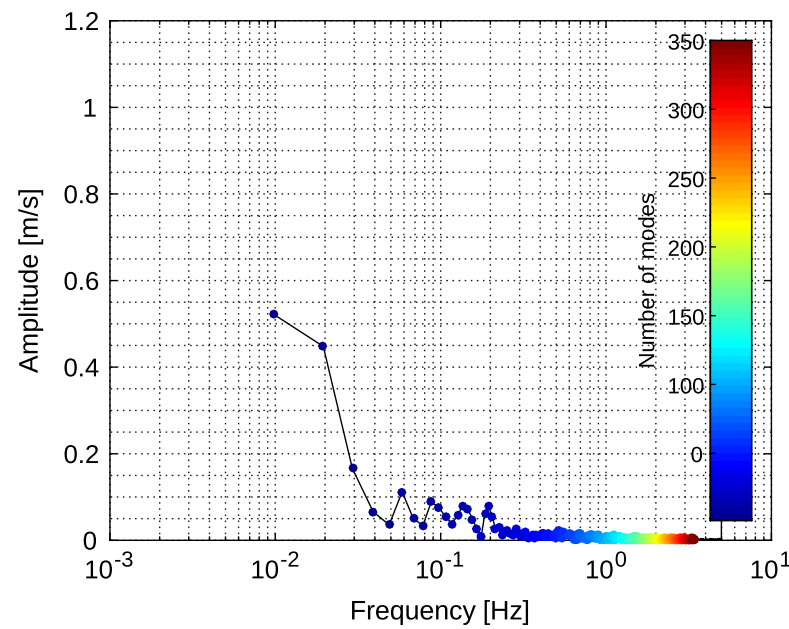

a) Amplitude and frequency for $T_{i}=\mathbf{5 \%}$

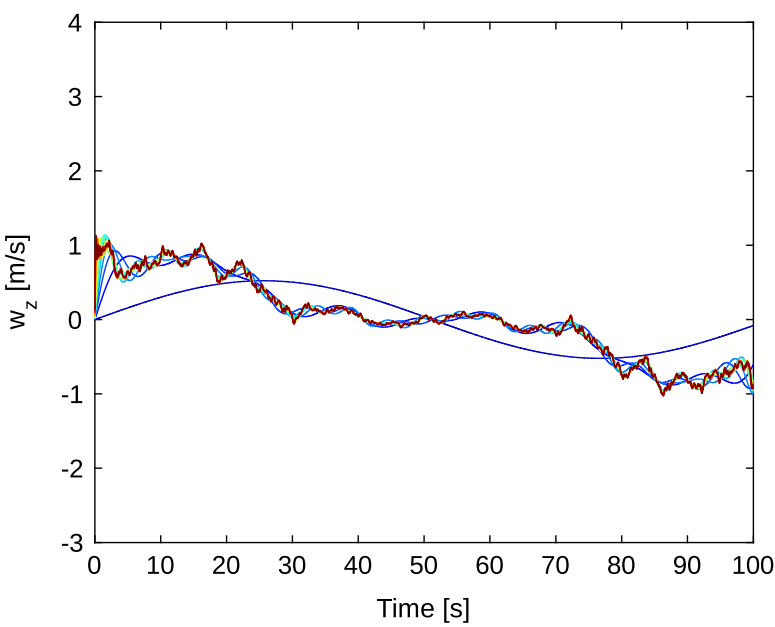

c) Wind time series for $T_{i}=5 \%$

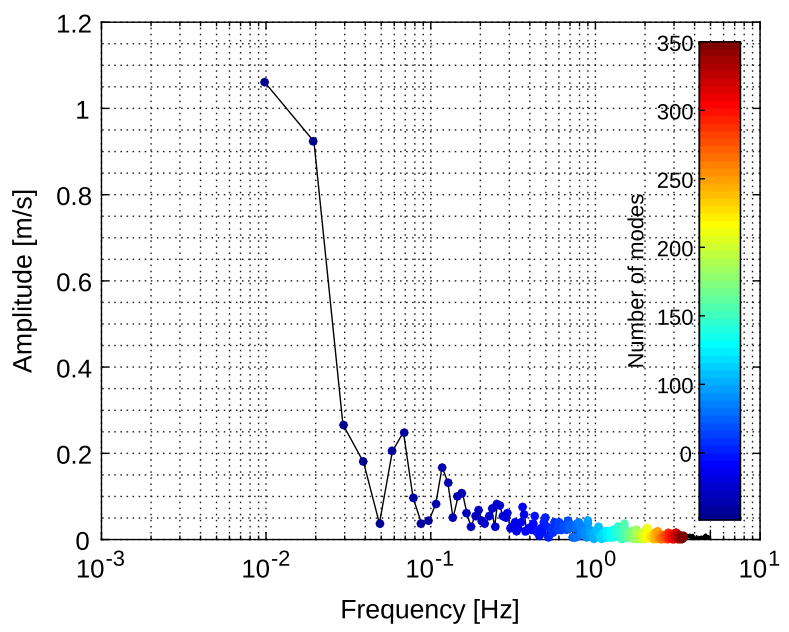

b) Amplitude and frequency for $T_{i}=15 \%$

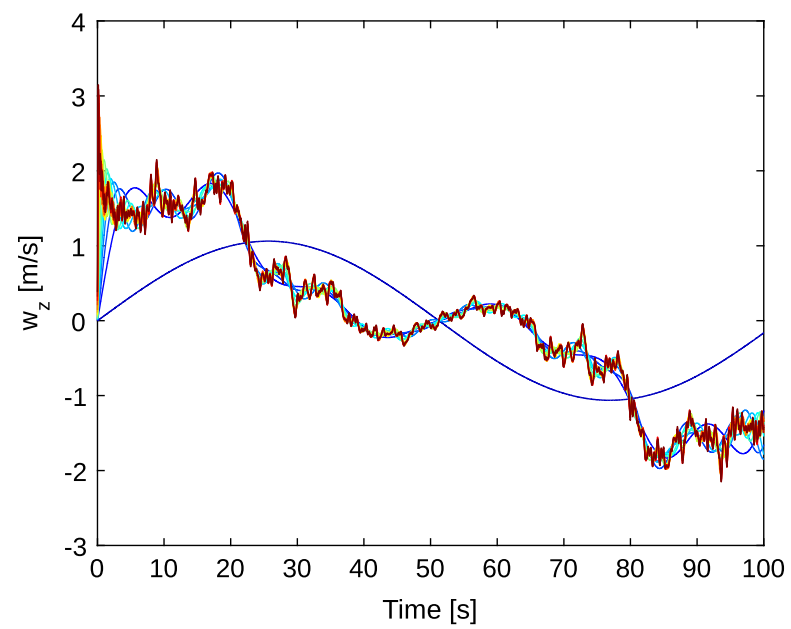

d) Wind time series $T_{i}=15 \%$

Fig. 5 Stochastic wind profiles for analysis.

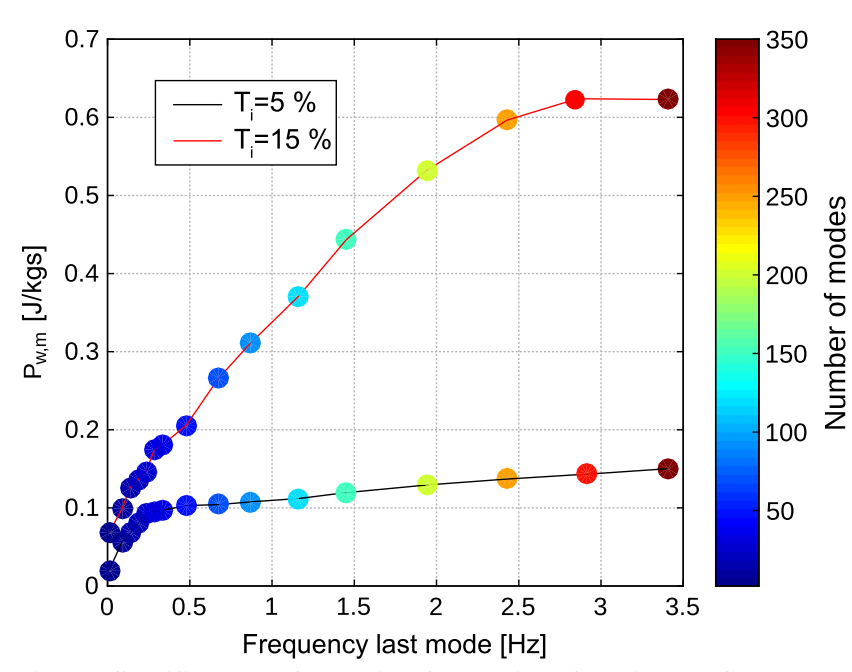

Fig. 6 Specific power from wind fluctuations for wind profiles generated with different numbers of modes.

\section{Methodology and Instrumentation for Experiments}

A. Bioinspired Surface Pressure Sensing

\section{Inspiration}

Ideas of dynamic energy transfer between moving atmosphere and flying vehicles have already come in the past from unfailing experience from nature. The airspace of SUAVs is very often shared with birds. Real-time sensing of the flow oncoming onto an aircraft is required to enable effective energy harvesting. Many sources in the literature claim that birds have natural sensory systems that enable them to detect and exploit atmospheric disturbances. According to Videler [35] and Scott and McFarland [36], birds use several flight strategies to gain energy and reduce the invested energy of flapping. Interaction of wind and obstacles such as buildings, hills, or waves generates an ascending component of air motion. Many birds with knowledge of soaring techniques use these updrafts to power their flight instead of wing flapping. In the case of unequal heating of the Earth's surface provoked by the punctured cloud layer implies an uplift of hot air, known as thermal. Eagles, condors, vultures, and many other large birds use these updrafts with a technique called thermal soaring in order to extend their endurance while searching for food. Another example is the sweeping flight within the gust pushed by waves. Gulls and pelicans use these gusts to power their flight by flying along the wave cliffs. Gaining speed while the wave slows down, they are able to pull up and glide to another wave where the process continues. Some birds such as kestrels remain motionless above a point on the ground by flying into the wind at a speed equal to that of the wind. This technique is called wind hovering.

Many biological studies report that there is a dense network of nerves around feather follicles. Feathers are connected to follicles in the skin, and they represent a very complex system of interconnected muscles and nerves. The primary function of such an anatomical configuration is mechanoreception. Specialized feathers on the head and breast have been shown to act as indicators of wind speed and direction. It has been also found that birds have very sensitive nerve endings (Herbst corpuscles) in their skin that can detect very high frequencies of vibrations of more than $100 \mathrm{~Hz}$. Severe turbulent flows 

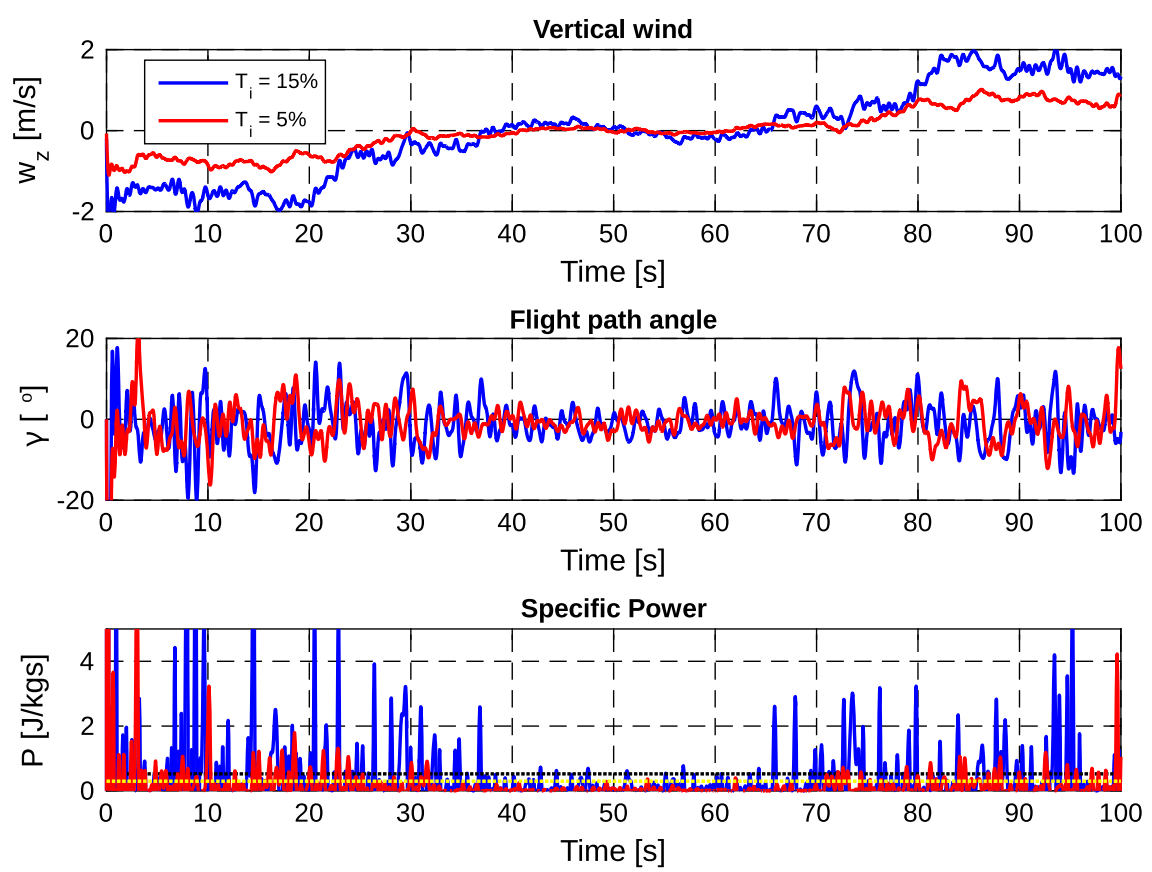

Fig. 7 Two-dimensional simulations for energy harvesting within stochastic profiles.

will cause the feathers to vibrate and gyrate wildly. As the feathers are elevated by the air stream, mechanoreceptors increase their discharge frequency according to Brown and Fedde [37]. However, identical copies from nature to man-made technologies are still not feasible for practical applications. It took millions of years for evolution to develop such extraordinary sensory systems and skills of natural flyers. On the other hand, an imaginative inspiration and transformation into technology are often based on various steps of abstraction.

\section{Local Angle of Attack from Pressure on Wing}

The paper from Gavrilovic et al. [38] reveals a system for the local angle of attack estimation based on pressure measurements on the wing. The idea implies that a certain pair of pressure ports is located on the wing, as shown in Fig. $\underline{8}$, where one port (pressure port $P_{1}$ ) is on the upper surface of the chosen section while the other is on the lower surface (pressure port $P_{2}$ ). A similar system has been recently used by Wood et al. [39]. Those points are recording a pressure difference with time, which has to be normalized with dynamic pressure in order to enable the effectiveness of the system for various airspeeds. A single location on the wing measures the pressure difference, and the estimation of the local angle of attack, including the influence of both aileron deflection, can be expressed with following Eq. (10). A detailed calibration process has been explained in the work of Gavrilovic [38],

$$
\alpha_{l}=C_{0}+C_{1}\left(\frac{p_{1}-p_{2}}{q}\right)+C_{2}\left(\frac{p_{1}-p_{2}}{q}\right)^{2}+C_{3} \delta_{a 1}+C_{4} \delta_{a 2}
$$

The calibration of the pressure sensors integrated into the flighttest vehicle was performed in controlled and repeatable conditions of the wind tunnel as shown in Fig. 9. The WindShape testing environment is composed of a rectangular module housing 162 coaxial fans and a filter for flow stabilization. The dimensions of the module are $1450 \times 850 \mathrm{~mm}$, and the speed range is between 0 and $14 \mathrm{~m} / \mathrm{s}$. As the aircraft had only rotational freedom of movement, the equality of the pitch angle delivered by the inertial measurement unit (IMU) and angle of attack was valid. Those conditions enabled sufficient data needed for the determination of constant coefficients found in Eq. (10). The constant coefficients in Eq. (10) were determined using the linear fit function that can be found in PYTHON.

\section{B. Test Vehicle and Equipment}

The chosen test vehicle is a $1.2 \mathrm{~m}$ flying wing shown in Fig. 10 . This type of aircraft could be representative of a powered drone that
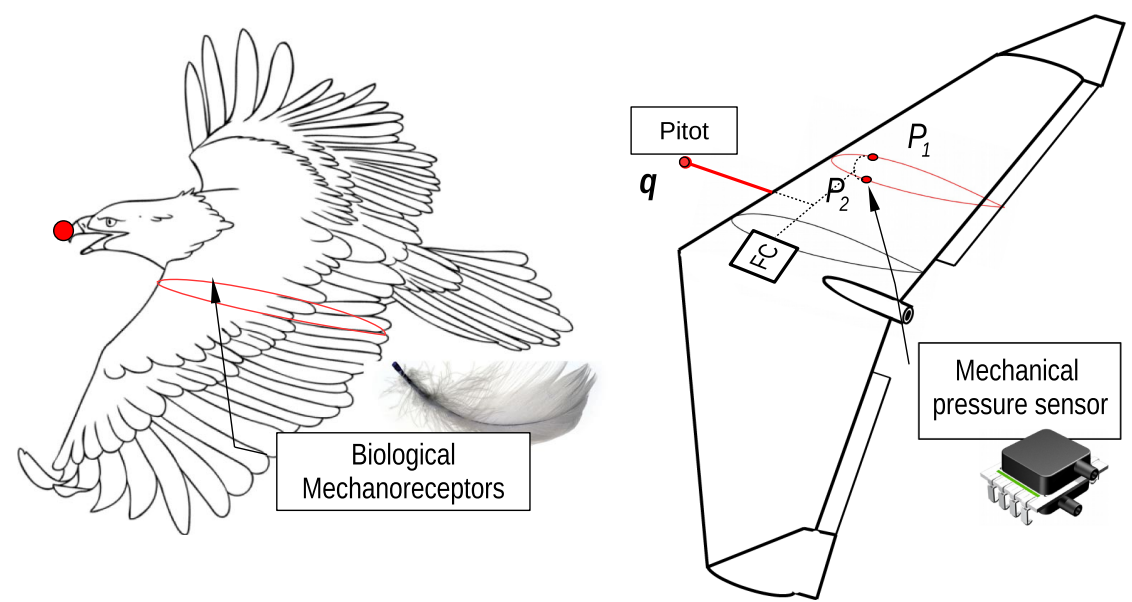

Fig. 8 Bionical approach. 
has been loaded with sensors and other payloads. The aircraft is equipped with an IMU integrated on the latest version of the Paparazzi [40] Chimera (shown in Fig. 11) autopilot system. The accelerations delivered from the IMU have been transformed into pitch

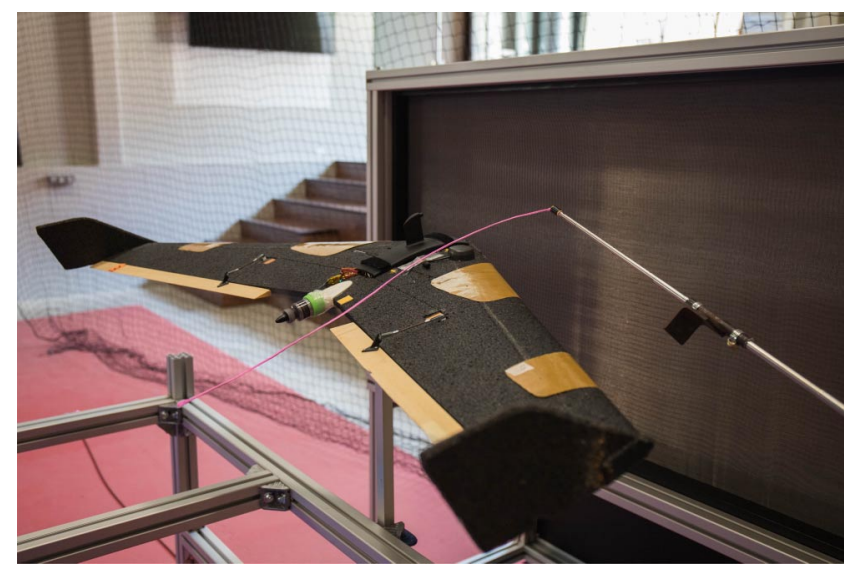

Fig. 9 Calibration process with WindShape.

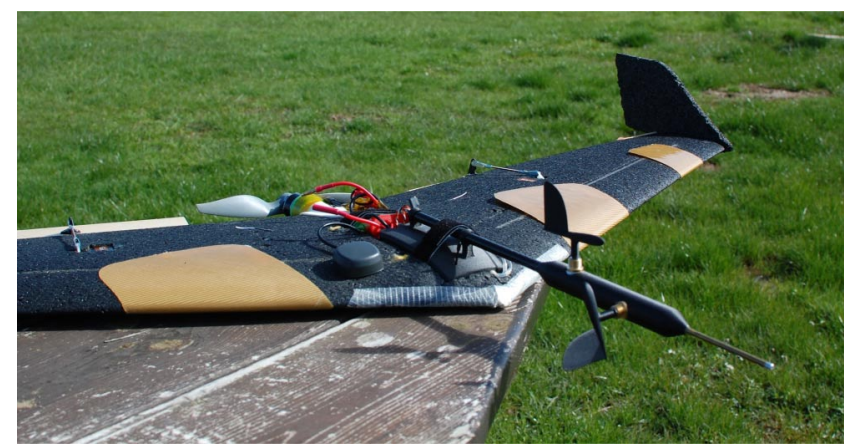

Fig. 10 Flight-test vehicle. and roll angles of the aircraft. The onboard equipment also includes a differential global positioning system (DGPS) enabling high precision for the estimation of climb and ground speed. The initial, prototype version of the aircraft incorporates several pressure sensors and specially fabricated and custom-designed aeroboom. The boom is designed to house two magnetic encoders connected with threedimensionally printed wind vanes and a pitot tube at its tip as shown in Fig. 10. The isolated system of the aeroboom itself delivers the angle of attack, slide slip, and airspeed information apart from local estimation on the wing from pressure sensors. Moreover, an additional sensor for motor power consumption was integrated into the system. It provides information on current consumption and voltage of the motor. The hardware information is summarized in Table 2 .

The flying vehicle was also equipped with a bioinspired system for the local angle of attack estimation from pressure measurements on the wing. In total, four locations were chosen on the wing. The farthest points were located at $75 \%$ of the wing half-span and will be from now on denoted as points 1 and 4 . Longitudinally, points were located near the center of gravity to avoid the induced angle of attack provoked by aircraft rotation. The chosen location of points 1 and 4 enabled the detection of the first appearance of a local stall on the wing. There were two more points located at $25 \%$ of the half-span wing. Those points are denoted as 2 and 3 . The purpose of using multiple locations for the local angle of attack estimation can be found in multiple useful functions. The first one is for being able to detect gusts with a length scale bigger than or equal to the distance between points. This condition would ensure that while penetrating the gust the aircraft would experience mainly pitching and heaving movements. It can serve as a decisive mechanism for the energyharvesting flight mode. The other purpose can be found in, for example, in-flight stall prevention. If the aircraft under any scenario approaches critical conditions of separation, the stall recovery system could bring the aircraft back to a stable state.

\section{Wind Estimation and Control Algorithm}

The attitude stabilization control laws from open-source autopilot system Paparazzi have been used directly without any modification.

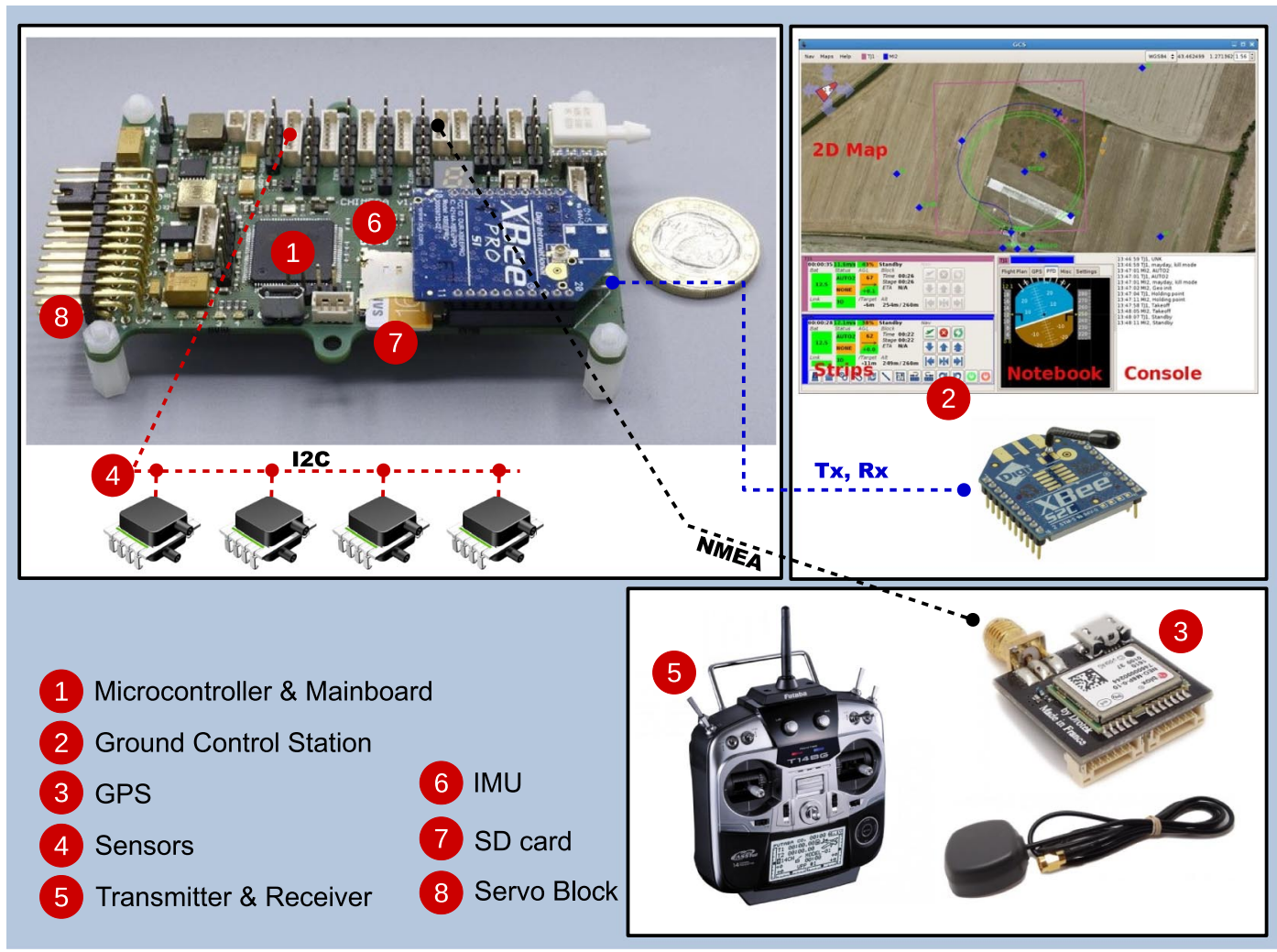

Fig. 11 Control architecture: Chimera autopilot system, version 1.0 (SD = Secure Digital). 
Table 2 Hardware description

\begin{tabular}{ll}
\hline \hline Description & \multicolumn{1}{c}{ Details } \\
\hline Autopilot board & Paparazzi Chimera version 1.0 \\
IMU & MPU-9150 \\
Differential pressure sensors & HCLA02X5EB \\
Magnetic encoder & MA3-P12-125-B \\
DGPS & Ublox NEO-M8P2 \\
\hline \hline
\end{tabular}

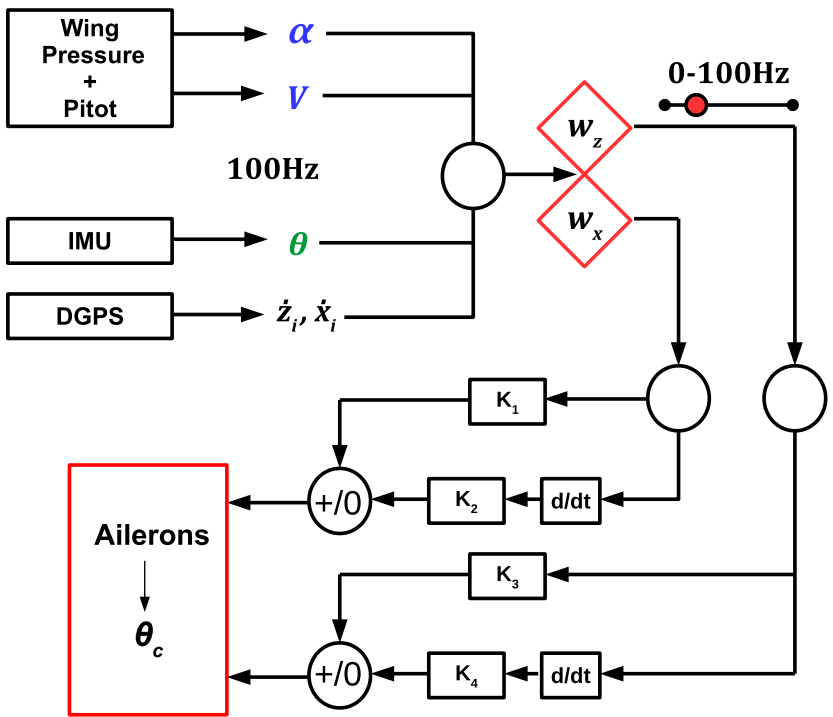

Fig. 12 Control law for energy harvesting: GUST mode.

Instead, the guidance control has been modified for the atmospheric energy extraction controller. Horizontal and vertical guidance controls are handled in a decoupled way in Paparazzi. To obtain the optimum pitch angle, it was sufficient to modify only the vertical guidance control, while the horizontal guidance has been kept as it is . As shown in Fig. 12, we estimate horizontal and vertical wind components from several parameters given by the onboard sensors. Based on longitudinal flight dynamics shown in Fig. 1, we have the following expressions for wind components:

$$
\begin{aligned}
& w_{x}=\dot{x}_{i}-V \cos (\theta-\alpha) \\
& w_{z}=\dot{z}_{i}+V \sin (\theta-\alpha)
\end{aligned}
$$

The method for two-dimensional wind field estimation has been previously demonstrated by Gavrilovic et al. [38]. The wind components and their derivatives are being multiplied with a set of constant gains, $K_{1}, K_{2}, K_{3}$, and $K_{4}$, as shown in Fig. 12 . Finally, the sum of the wind component multiplied by a proportional gain and its derivative is used to define the optimum pitch angle and given directly to vertical guidance control as the desired pitch angle $\theta_{c}$. Vertical guidance control affects both the pitch angle and the throttle level. We have used a mode in which the desired pitch comes from the optimum pitch calculations. Moreover, we are able to fix the throttle to a predefined value that can be modified by a slider during the flight. The previously described control strategy has been incorporated in a special autopilot mode for energy harvesting called GUST. As there were four locations on the wing for the angle of attack estimation, they served as a decisive mechanism for energy extraction control. If all four sensors provided outputs with a difference of less than a 5\%, GUST mode would be activated, and ailerons would act based on estimated wind velocity components. On the contrary, aileron input would be canceled. This condition was imposed to ensure that pitching up or down was performed for sufficiently large length scales of a gust to warrant energy extraction. More precisely, if the length scale of the wind is equal to or larger than a wing span, the aircraft will perform energy-harvesting maneuvers. The update rate for data acquisition from pressure and inertial sensors is 100 times/s. On the other hand, data used for control input can be filtered in real time with a rate chosen via the ground control station in flight.

In the AUTO 2 control of Paparazzi, the vertical control loop controls the pitch and the throttle according to the climb speed set point, which comes from the altitude error. First, the altitude error is computed between the altitude set point of the trajectory and the actual altitude estimated at the current point. The estimation of the current altitude uses the DGPS measurements and the altitude calculated from static pressure measurements obtained from the onboard barometer. Then, the climb speed set point is computed proportionally to the altitude error with an addition of a constant preclimb command. Afterward, the pitch angle and throttle set points are calculated by traditional proportional-integral-derivative control using the climb speed set-point error. The resultant throttle set point is smoothed out through a slew function and then sent to the motor directly. However, the pitch angle set point is sent to the cascaded inner attitude control loop where the allocated elevator commands are computed and then sent to the corresponding control surface actuator(s). The AUTO 2 mode has been primarily used for loitering, altitude hold missions.

\section{A. Outdoor Flight-Testing Procedure}

The outdoor flight-testing procedure was performed in early summer at the local air-model club in southern France, with coordinates of the test location $43^{\circ} 27^{\prime} 44.8^{\prime \prime} \mathrm{N}-1^{\circ} 16^{\prime} 23.5^{\prime \prime} \mathrm{E}$. The flight region shown in Fig. 13 is composed of moderate hills and the vast valley at the end. The controller used in this work enables a total of four modes that can be chosen manually from the remote-control

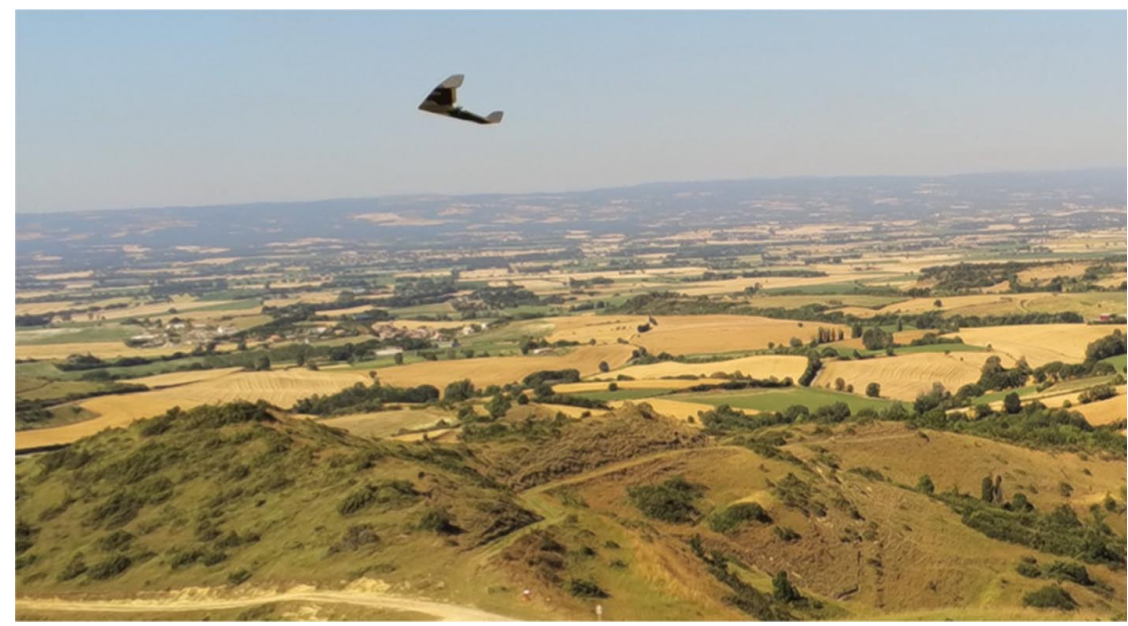

Fig. 13 Flight-test site in southern France. 

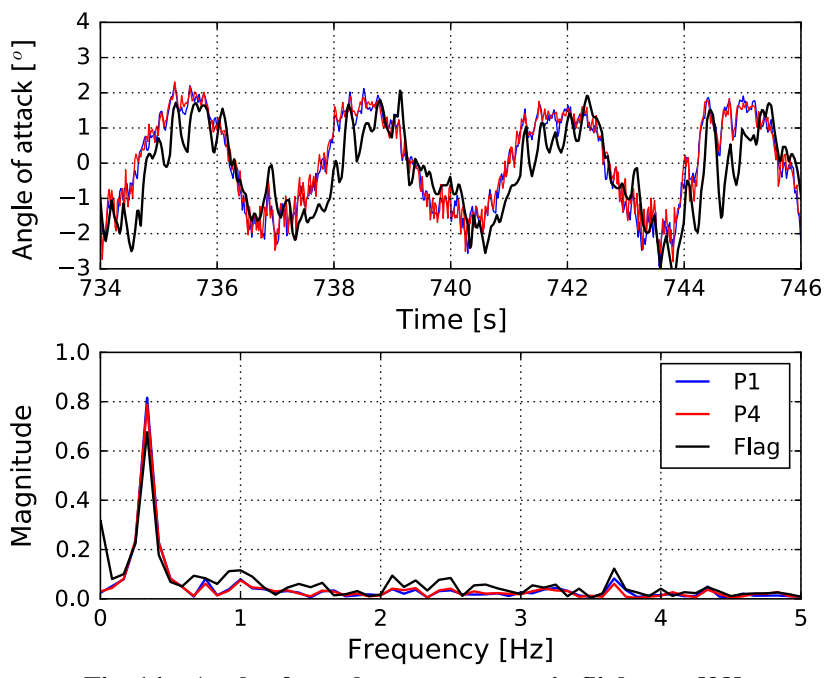

Fig. 14 Angle of attack measurements in flight test [38].

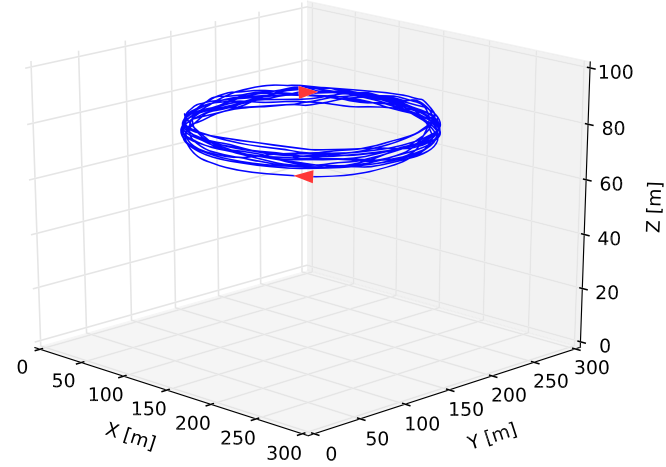

a) Trajectory for 12 circles with diameter $200 \mathrm{~m}$ on the first day

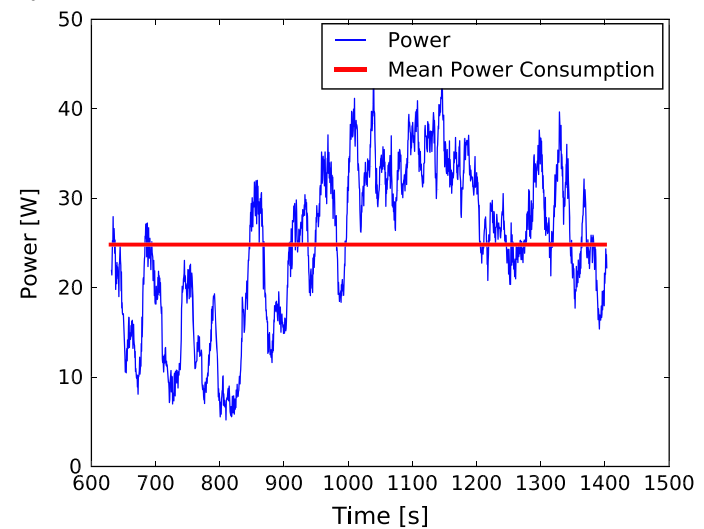

c) Motor electrical power consumption for $13 \mathrm{~min}$ with average $25 \mathrm{~W}$ on the first day

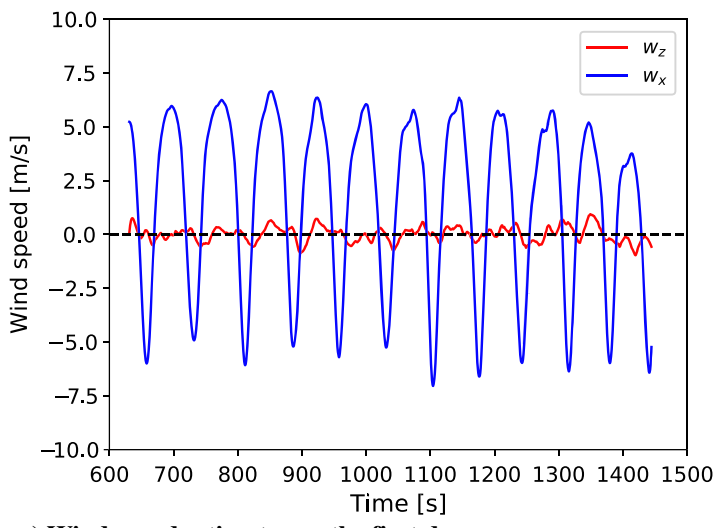

e) Wind speed estimates on the first day transmitter. The first mode is fully manual with respect to the pitch, roll, and thrust input of the pilot. The second mode is semi-automatic (AUTO 1), in which aircraft perform stabilization in a roll while still respecting pilot inputs. The third mode is fully autonomous (AUTO 2), in which aircraft follow predefined trajectories (either a circle, hippodrome, or points), maintaining specified altitude. Finally, the fourth mode (GUST) is related to energy-harvesting flight. In this mode, the aircraft follows the given trajectory while performing autostabilization in roll and energy-harvesting maneuvers. The inflight wireless communication between the aircraft and ground control station allows real-time insight on flight parameters, modification, and definition of the flight path and tuning of various control gains. It also provides a real-time plotting of any sensor output.

\section{B. Angle of Attack Measurements}

The system used in this Paper uses two different approaches for the angle of attack estimation. Some initial flight tests served to compare and verify coherence between two systems. Those tests were performed with calibrated constant coefficients for a pressure-based

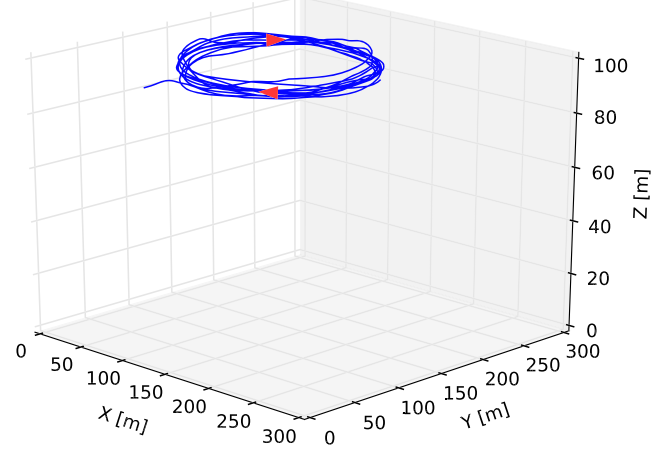

b) Trajectory for ten circles with diameter $150 \mathrm{~m}$ the second day

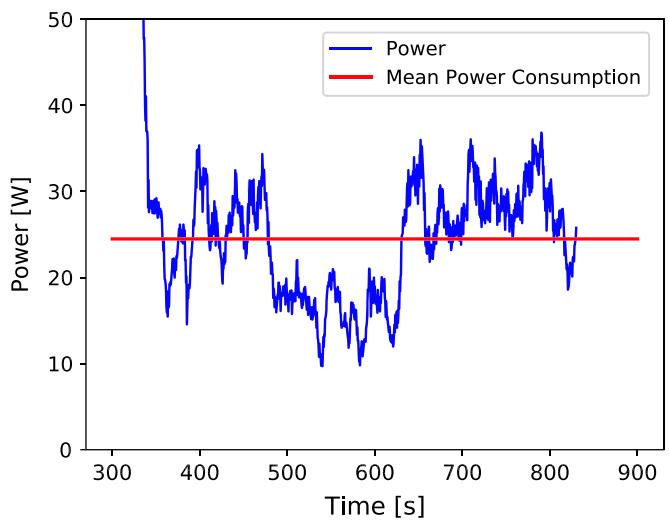

d) Motor electrical power consumption for $10 \mathrm{~min}$ with average $24 \mathrm{~W}$ on the second day

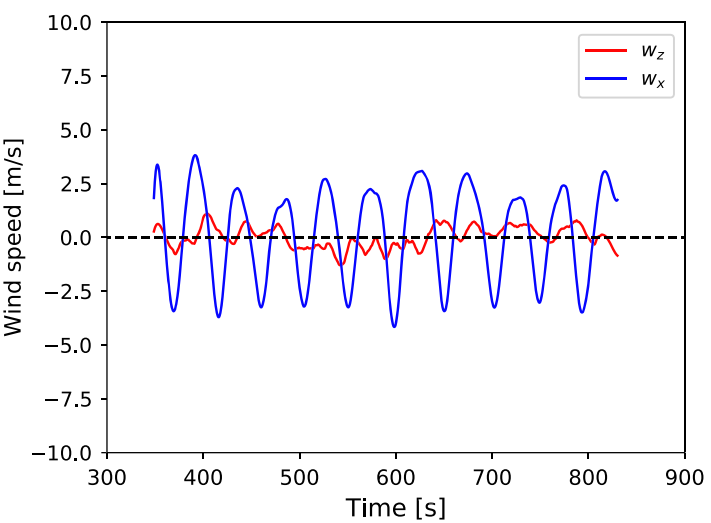

f) Wind speed estimates on the second day

Fig. 15 Altitude hold task (AUTO 2 mode): loitering flight for determination of average power consumption. 
angle of attack [shown in Eq. (10)] determined from wind tunnel sensor calibration as shown in Fig. 9 . The results presented in Fig. 14 show that angle of attack estimation from pressure measurements on the two farthest locations on the wing has high coherence with one delivered by a wind vane (please see Fig. 10 for aeroboom). The oscillations shown in the graph were made with preprogrammed aileron input with chosen frequency and magnitude of sinusoidal function. The spectrum analysis reveals that there is a certain difference in magnitude for the highest peak. Because of the inertia of the wind vane, one can notice a slight rise in magnitude. The effect of inertia is even higher for flight within stronger winds. Besides the potential for gust length-scale determination (that can be incorporated as a decisive mechanism) and development of a stall recovery system, it can be concluded that pressure measurements on the wing provide a more reliable estimation of the angle of attack when compared to wind vane option, particularly for a flight with strong wind fluctuations. Therefore, the angle of attack estimation will further be based only on pressure measurements on the wing.

\section{Average Power Consumption}

Several flights were performed to determine the average power consumption of the motor while performing predefined circle trajectories at a given altitude. The flight controller was set for AUTO 2 mode, with the purpose of maintaining the predefined trajectory path while correcting the altitude with thrust input. The first flight, shown in Fig. 15, was performed over flat terrain with moderate wind conditions (average around $5 \mathrm{~m} / \mathrm{s}$ ). It can be seen in Fig. 15e that the vertical wind component was most of the time below $\overline{0.3} \mathrm{~m} / \mathrm{s}$. The average power consumption of the motor for
14 circles was $25 \mathrm{~W}$. The second flight shown in Fig. 15b was performed within weak wind conditions (up to $2.5 \mathrm{~m} / \mathrm{s}$ ) in which the average power consumption shown in Fig. 15d of $24 \mathrm{~W}$ was found for ten circles.

\section{Autonomous Flight to Exploit Thermals}

The initial version of the energy-extraction controller mode (GUST) was designed in a way to have all the elements of AUTO 2 mode with an exception for the freedom of pitching up or down motion. Besides, the aircraft still follows the given trajectory in a horizontal plane ( $x-y$ plane) and remains stable in the roll. It reacts according to the estimated wind component and corresponding control law for energy harvesting. The particular flights presented in Fig. 16 are energy harvesting from quasi-stationary updraft. The flights presented in Figs. 16 and 17 are performed with GUST mode. The weather conditions at that particular day enabled strong formations of rising air.

Although soaring in updraft conditions does not assume exploitation of wind gradients, the flight strategy applied was used to test the effectiveness of the controller, wind estimation, and average electrical power consumption. The controller, in this case, uses only proportional gain multiplying the estimated vertical wind component, while other gains are set to zero. This will enable the aircraft to pitch up in case of an updraft. Also, the system compares the coherence of angle estimation from pressure measurements on the wing, allowing the controller to act within a sufficiently large length scale of the updraft. When compared to the loitering mission (altitude hold task performed on the same day) shown in Fig. 15, soaring within thermal shown in Fig. 16 resulted in around $\overline{50 \%}$ less electrical power

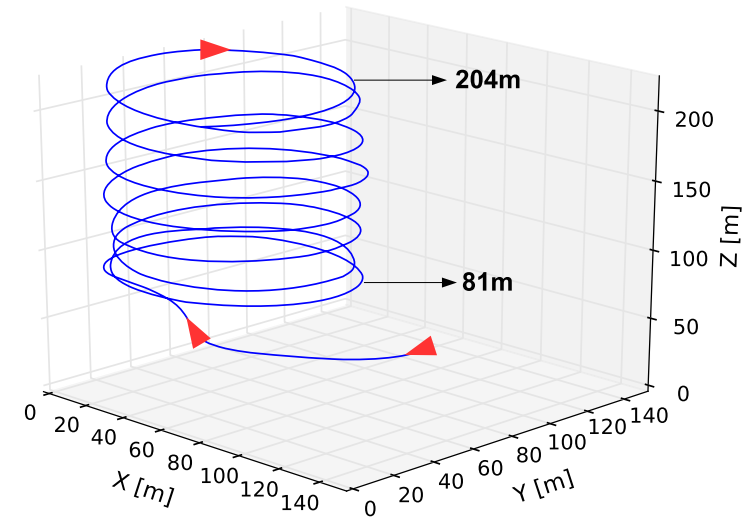

a) Trajectory of the aircraft within thermal 1

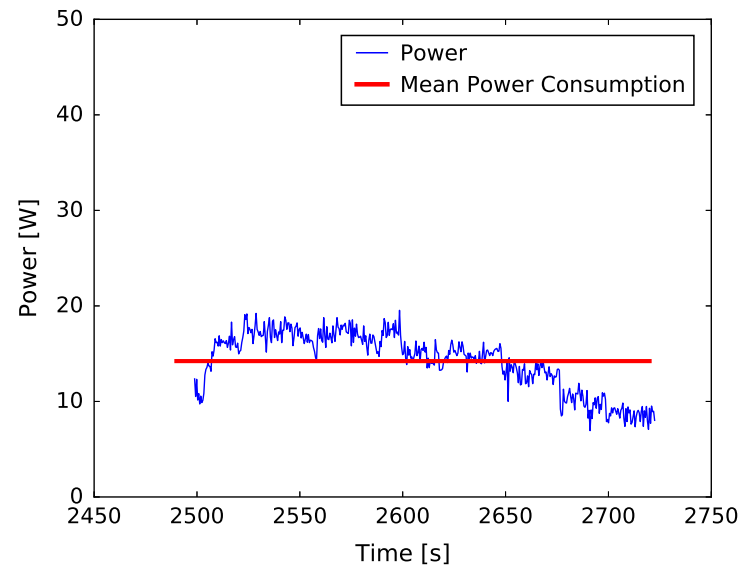

b) Motor electrical power consumption for $4 \mathrm{~min}$, average $13.5 \mathrm{~W}$

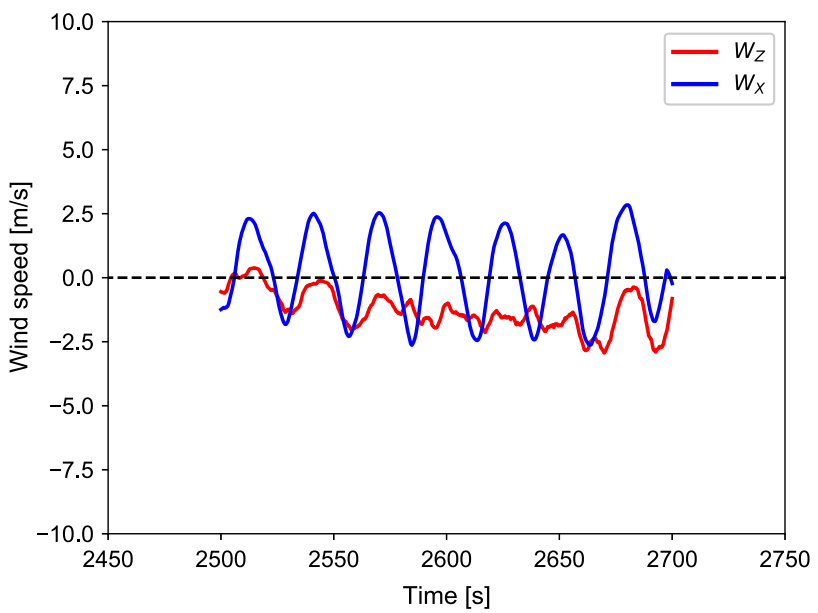

c) Estimated wind components

Fig. 16 Autonomous flight to exploit thermal on the first day. 


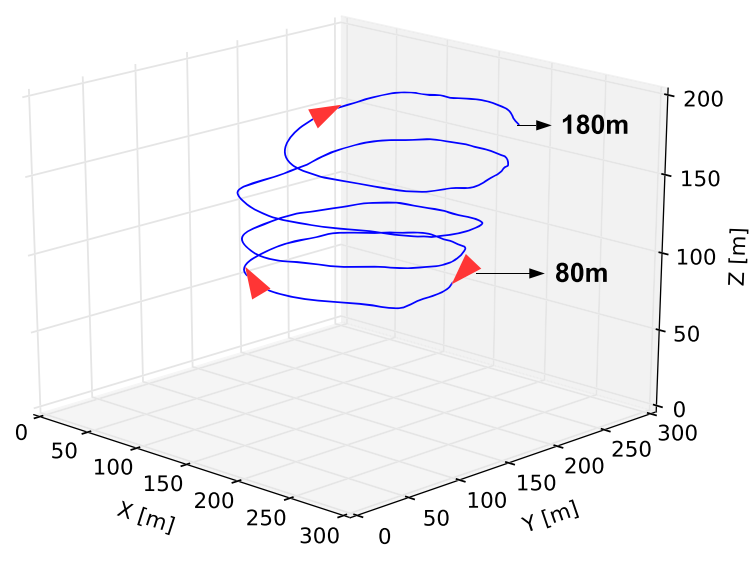

a) Trajectory of the aircraft within thermal 2

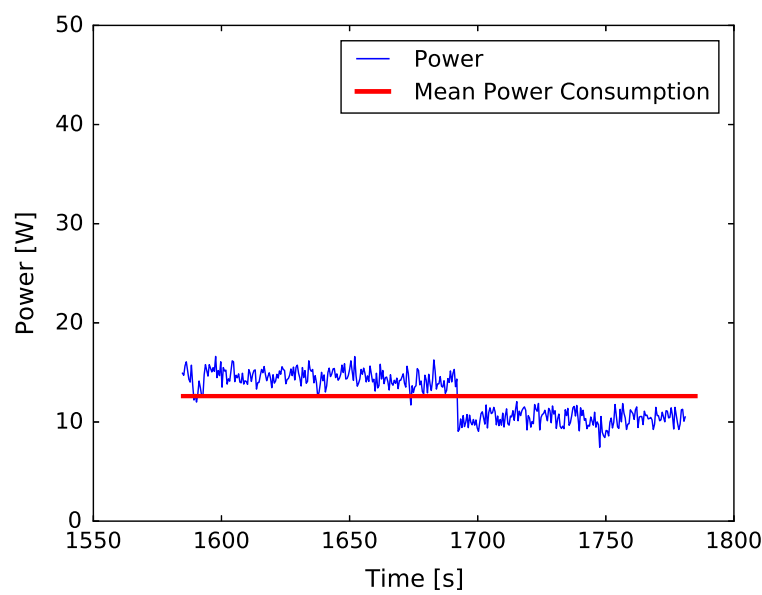

b) Motor electrical power consumption for $3 \mathrm{~min}$, average $11 \mathrm{~W}$

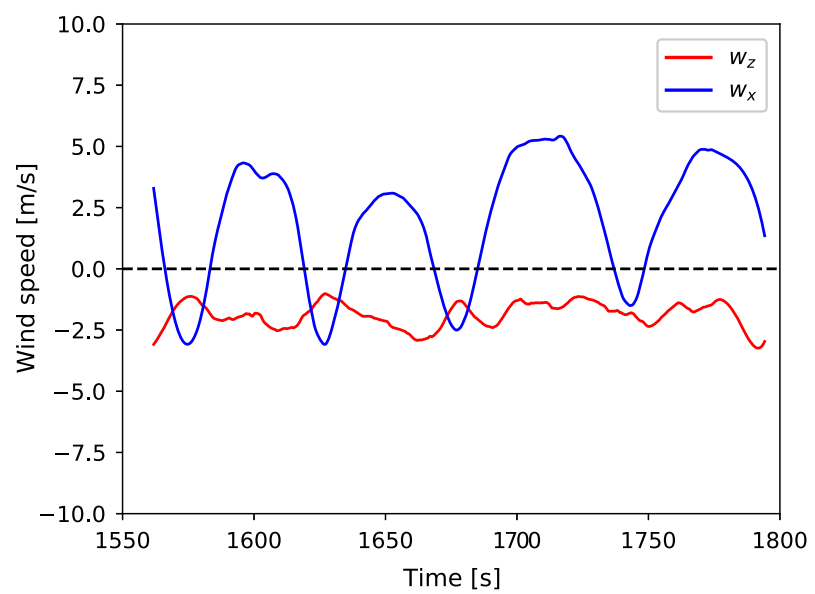

c) Estimated wind components

Fig. 17 Autonomous flight to exploit thermal on the second day.

invested and $123 \mathrm{~m}$ of altitude gain in the same time for $4 \mathrm{~min}$ of flight. The second flight presented in Fig. 17 was performed on the other day, resulting in $60 \%$ less electrical power consumption and $100 \mathrm{~m}$ of altitude gain. It is interesting to notice that as the strength of the vertical wind was growing, as shown in Fig. 16c, the motor power consumption was reduced in Fig. 16b. The results, of course, refer to atmospheric conditions experienced on a particular day and location. The nature of the atmosphere, especially nowadays, does not guarantee the repeatability of the exact same conditions. However, the results show that significant gains can be achieved by using biologically inspired sensory systems and flight techniques.

\section{E. Exploitation of Horizontal Wind Gradient: Dynamic Soaring}

The following part of the experimental campaign was performed within a strong wind shear formed after the rising hill. On that particular day, the aircraft was flown with strong wind conditions in which the horizontal wind velocity went up to $8 \mathrm{~m} / \mathrm{s}$ with increasing altitude. The aircraft was initially aligned with the upcoming wind with semi-automatic mode (AUTO 1), from where the fully autonomous mode for energy harvesting (GUST) was activated. A small portion of the initial flight is presented in Fig. 18, while the whole cycle is shown in Fig. 19. The flight segment and corresponding case for power maximization are shown in Fig. 18b. The flight segment shows the ascent within the positive horizontal wind gradient. The flying maneuver presented in Fig. 18 is in accordance with the flight case for aircraft specific power maximization within wind shear from Lawrance and Sukkarieh $[\underline{41}, \underline{42}]$ and Gavrilovic et al. $[24,25]$. This flight can also be presented as an initial maneuver for neutral energy cycles of albatross flight while doing dynamic soaring. The results have demonstrated that the aircraft performed a pitching maneuver for aircraft power maximization within a strong wind gradient. During the maneuver, the control system was relying on gains $K_{1}$ and $K_{2}$, which multiply the horizontal wind component and its derivative. Moreover, the flight within such a strong wind was accomplished with only $5 \mathrm{~W}$ of average motor consumption, which is five times less than what was found to be needed for the altitude hold task. It is important to notice from Fig. 18a that during the pitching maneuver within the positive gradient, $\overline{\partial w_{x}} / \partial z>0$, the aircraft airspeed remained constant. This means that the gain in kinetic energy from the wind gradient was transformed into potential energy and was therefore free climbing.

A bigger picture of the whole cycle shown in Fig. 19a illustrates the combination of altitude hold (with autostabilization AUTO 2 mode) and energy-harvesting flight (GUST). The cycle was initiated with GUST mode, in which aircraft were mainly climbing within the presence of horizontal wind gradient while maintaining a constant level of airspeed. After reaching a certain altitude level, the aircraft was manually put into AUTO 2 mode with a mission to autonomously come back to initial altitude while still following predefined hippodrome trajectory. As can be seen in Fig. 19b, after $100 \mathrm{~s}$ of energyharvesting flight, the aircraft entered autonomously into zero-thrust gliding toward the initial altitude. The overall motor consumption during the whole cycle was around $9 \mathrm{~W}$, which is almost three times less than what was found for altitude hold flight. Moreover, the aircraft still had an excess of potential energy after reaching the initial point of the cycle. 

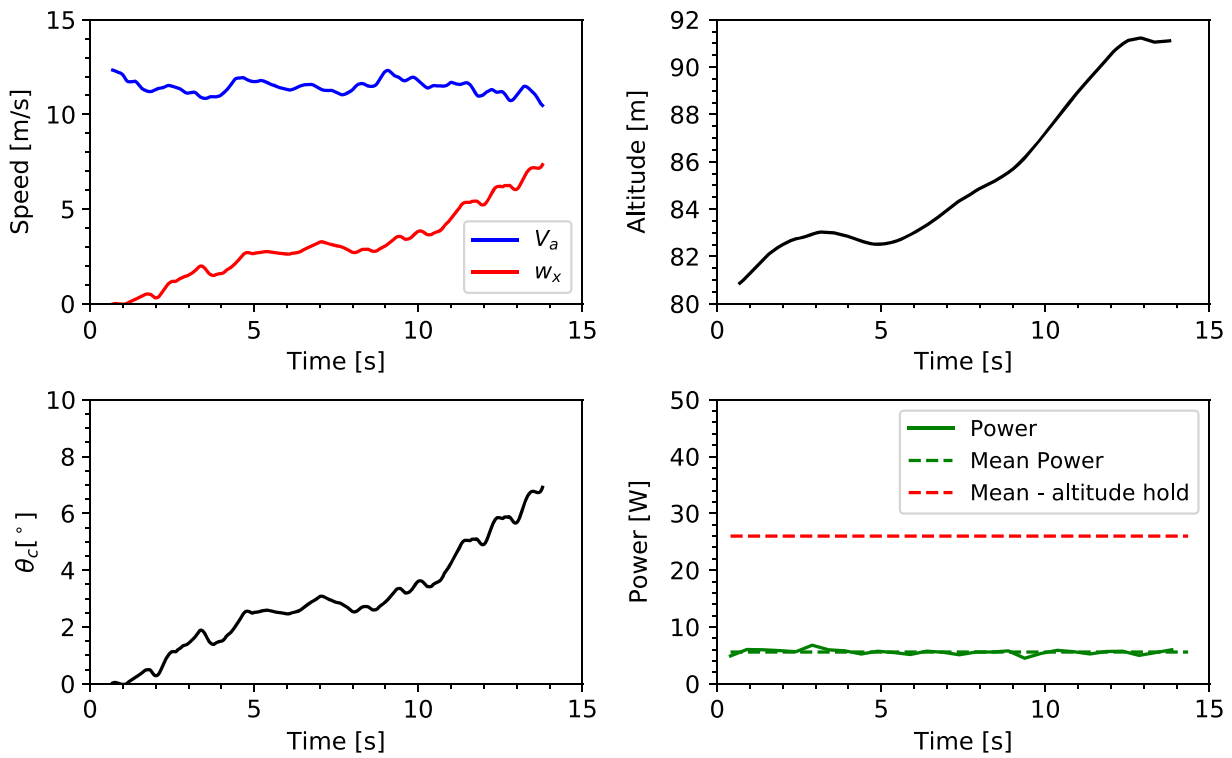

a) Flight parameters within horizontal wind gradient $\partial w_{x} / \partial z>0$

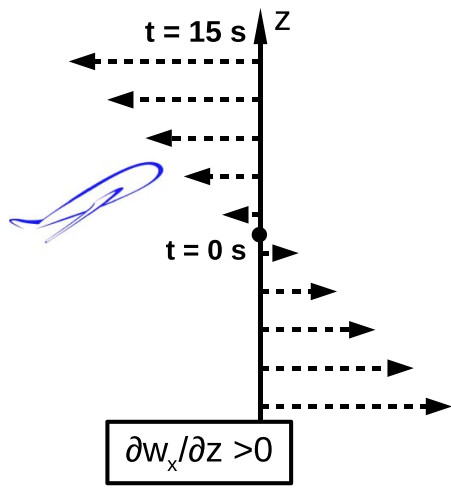

b) Flight maneuver for specific power maximization in wind shear

Fig. 18 Autonomous flight to exploit horizontal wind gradients.

\section{Conclusions}

The simulations presented in this Paper reveal the advantages and possibilities of flight using the mechanism of energy harvesting from atmospheric phenomena. Different flight scenarios have been studied for flight within the sinusoidal gust profile. It was found that energy harvesting can bring significant benefits through reduced necessary thrust to perform altitude hold tasks. The overall power required between different flight scenarios was compared, and it was found that energy harvesting provides significant savings in invested power. Moreover, the influence of various combinations of frequencies and magnitudes of sinusoidal gust have been investigated. It was found that an increase in the magnitude of the sinusoidal profile brings a significant increment in the amount of energy harvested. The second analysis was dealing with simulations related to the potential of energy harvesting for flight within a stochastic profile generated from the Kaimal spectrum for two different turbulence intensities. It was found that a more energetic turbulence profile provides potentially more energy for harvesting.

The second part of this Paper was related to the development and application of a biologically inspired sensory system for the local angle of attack estimation from pressure measurements on the wing. A basic system for wind field estimation using commercially available sensors has been presented. The initial flights were performed to determine the mean electrical power consumption for an altitude hold task with a given trajectory. The first energy-harvesting flight campaign was performed over flat terrain with a strong presence of thermals. Even though this Paper is not strictly related to thermal soaring, the designed controller for energy harvesting proved to be efficient that day, bringing around $120 \mathrm{~m}$ of altitude gain with $50 \%$ less motor power consumption when compared to a loitering mission. The second phase of the experimental campaign revealed that the energy-harvesting controller enables the aircraft to perform necessary pitching maneuvers for power maximization while flying within a strong spatial wind gradient. Moreover, it was found that energyharvesting flight, while performing a hippodrome cycle, can be performed with almost three times less average invested power when compared to only altitude hold task. The aircraft was exploiting wind gradient while climbing with a constant airspeed in the first part of the hippodrome cycle and in the second, after a certain altitude it glided toward initial level.

The energy gain from wind fluctuations investigated using flight simulations can be connected to experimental results through the last part of the equation for aircraft specific power. In both cases, the vehicle was performing maneuvers intending to benefit from the last part of the specific power equation that contains wind derivatives. This part represents the gain in kinetic energy, which is being transformed in reduced necessary power for flight. The difference can be found in the repetitive behavior of a sinusoidal profile, while in real flight, this Paper has used large-scale gradients. The theoretical results also show that energy harvesting from wind fluctuations (stochastic wind profile with $T i=5$ and $15 \%$ ) brought a relatively small amount of energy to the aircraft when compared to the power required for flight. Therefore, the experimental test campaign focused on largescale atmospheric phenomena, as thermal and dynamic soaring. 


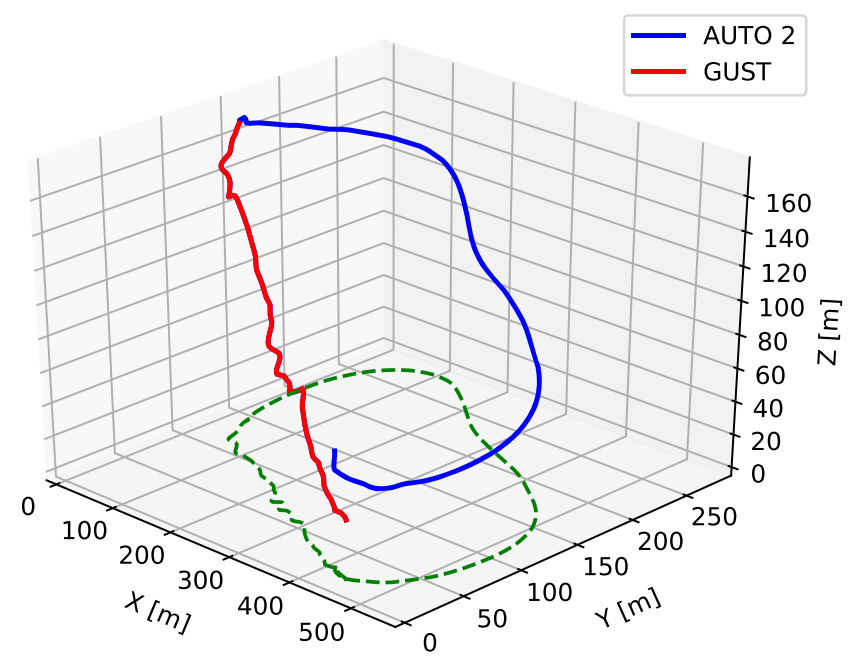

a) Trajectory of the aircraft within hippodrome cycle
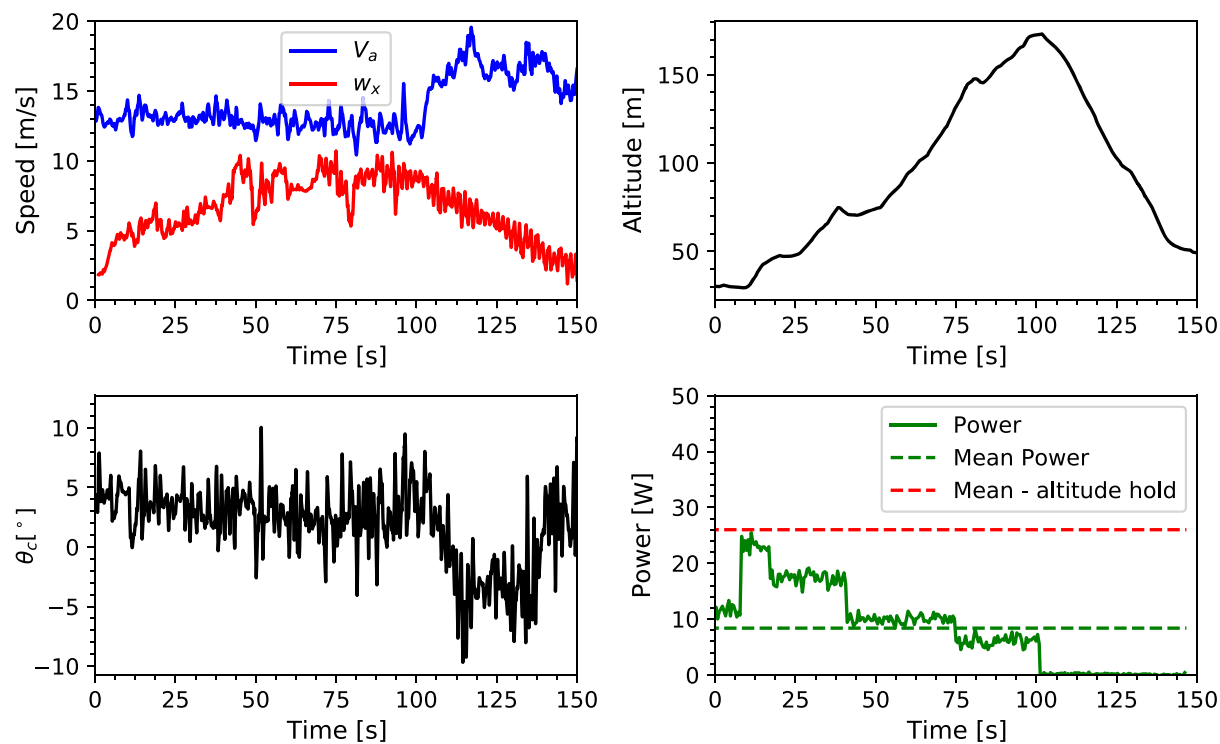

b) Flight parameters for specific power maximization in wind shear

Fig. 19 Autonomous flight to exploit horizontal wind gradients within a hippodrome cycle.

It should be noted that the presented flight-test campaign intended to demonstrate that the significant benefits can be achieved while exploiting atmospheric phenomena with a $1.2 \mathrm{~m}$ fixed-wing vehicle. Having in mind that the control used in this Paper is optimal only for certain wind strengths, the research opens a possibility for a new study related to the improvement of the control law, providing the opportunity to the vehicle to benefit optimally from different wind scenarios simultaneously. Although the bioinspired sensory system provides precise information about the experienced wind conditions, the authors consider that advanced knowledge of the wind field would provide necessary awareness for path planning with more sophisticated optimal control by using, for example, miniaturized laser or sonic detection systems in the future.

\section{Appendix :Aircraft Properties}

The aircraft steady aerodynamic coefficients have been determined using the Athena Vortex Lattice program designed by Professor Mark Drela from Massachusetts Institute of Technology. The software has been modified to take into account the viscous effects. Each section of the wing is treated according to its Reynolds number and corresponding viscous polar. The viscous drag coefficient in this study has been taken as a function of the total angle of attack seen by each section and the corresponding Reynolds number. Such innovation provides an upgrade for polar [shown in Eq. (A3)] estimation for a single flight speed. The aircraft lifting surfaces are shown in Fig. A1, and the corresponding aerodynamic derivatives are shown in Table A1.

The simulations in Sec. II assume the following representation of main aerodynamic coefficients:

$$
\begin{aligned}
C_{L}= & C_{L 0}+C_{L \alpha} \alpha+C_{L \dot{\alpha}} \frac{\dot{\alpha} l}{2 V}+C_{L \dot{\theta}} \frac{\dot{\theta} l}{2 V} \\
& +\sum_{\text {Control }}\left(C_{L \delta} \delta+C_{L \dot{\delta}} \frac{\dot{\delta} l}{2 V}+\ldots\right) \\
C_{M}= & C_{M 0}+C_{M \alpha} \alpha+C_{M \dot{\alpha}} \frac{\dot{\alpha} l}{2 V}+C_{M \dot{\theta}} \frac{\dot{\theta} l}{2 V} \\
& +\sum_{\text {Control }}\left(C_{M \delta} \delta+C_{M \dot{\delta}} \frac{\dot{\delta} l}{2 V}+\ldots\right)
\end{aligned}
$$

$$
C_{D}=5 \times 10^{-6} \alpha^{4}-4 \times 10^{-5} \alpha^{3}+4 \times 10^{-4} \alpha^{2}+3.2 \times 10^{-3} \alpha
$$$$
+0.0409
$$ 


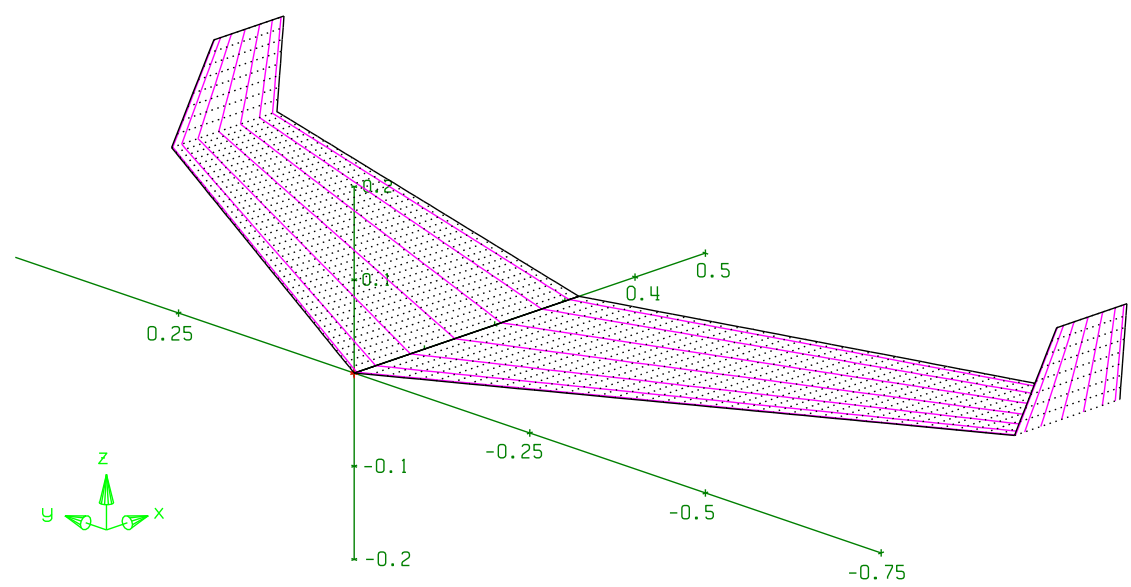

Fig. A1 Lifting surfaces for vortex lattice program.

Table A1 Aerodynamic properties

\begin{tabular}{ll}
\hline \hline Parameter & \multicolumn{1}{c}{ Value } \\
\hline Wingspan & $1.2 \mathrm{~m}$ \\
Airfoil & Sipkill $1.7 / 10$ \\
Mean aerodynamic cord & $0.27 \mathrm{~m}$ \\
Wing surface & $0.26 \mathrm{~m}^{2}$ \\
Mass & $0.75 \mathrm{~kg}$ \\
Cruise speed & $12 \mathrm{~m} / \mathrm{s}$ \\
Aspect ratio & 7 \\
$I_{y y}$ & $0.1 \mathrm{~kg} \cdot \mathrm{m}^{2}$ \\
$C_{L o}$ & 0.32 \\
$C_{L \alpha}$ & $5.12 / \mathrm{rad}$ \\
$C_{L q}$ & $13.78 / \mathrm{rad}$ \\
$C_{L \dot{\alpha}}$ & $f(\mathrm{~Hz}, \mathrm{~m})$ \\
$C_{L \delta_{e}}$ & $-0.5 / \mathrm{rad}$ \\
$C_{M \alpha}$ & $-3.33 / \mathrm{rad}$ \\
$C_{M q}$ & $-19.83 / \mathrm{rad}$ \\
$C_{M \dot{\alpha}}$ & $f(\mathrm{~Hz}, \mathrm{~m})$ \\
$C_{M \delta_{e}}$ & $-0.0462 / \mathrm{rad}$ \\
\hline \hline
\end{tabular}

\section{References}

[1] Peter, K., "Analysis of the European Wind Power Climatology and the Possible Cosmic Radiation Forcing on Global Lightning Activity," Ph.D. Thesis, Faculty of Science, Graduate School in Physics, Eotvos Lorand Univ., Budapest, Hungary, 2013.

[2] Phillips, J. H., "Propulsive Effects due to Flight Through Turbulence," Journal of Aircraft, Vol. 12, No. 7, 1975, pp. 624-626. https://doi.org/10.2514/3.44480

[3] Patel, C. K., and Kroo, I., "Control Law Design for Improving UAV Performance Using Wind Turbulence," AIAA Aerospace Sciences Meeting and Exhibit, AIAA Paper 2006-0231, 2006. https://doi.org/10.2514/6.2006-231

[4] MacCready, P., "Optimum Airspeed Selector," Soaring, Vol. 10, No. 11, 1958, pp. 10-11.

[5] Edwards, D., "Autonomous Locator of Thermals (ALOFT) Autonomous Soaring Algorithm," Naval Research Lab. TR NRL/FR/5712-15$10,272,2015$.

[6] Gudmundsson, V., Golubev, V., Drakunov, S., and Reinholtz, C., "Biomimetic Opportunistic Approaches in Energy-Conserving/Harvesting Flight-Path Modeling for UAS," AIAA Modeling and Simulation Technologies Conference, AIAA Paper 2016-3676, 2016.

[7] Gudmundsson, V., Golubev, V., Drakunov, S., and Reinholtz, C., "A Biomimetic Energy-Conserving/Harvesting Trajectory Planning for a sUAV," AIAA Atmospheric Flight Mechanics Conference, AIAA Paper 2016-3889, 2016.

[8] Zhao, J., "Optimal Patterns of Glider Dynamic Soaring," Optimal Control Applications and Methods, Vol. 25, No. 2, 2004, pp. 67-89. https://doi.org/10.1002/(ISSN)1099-1514

[9] Bonnin, V., "Energy-Harvesting Mechanism for UAV Flight by Dynamic Soaring," International Journal of Micro Air Vehicles, Vol. 7 ,
No. 3, 2015, pp. 213-229. https://doi.org/10.1260/1756-8293.7.3.213

[10] Liu, D.-N., Hou, Z.-H., Guo, Z., Yang, X.-X., and Gao, X.-Z., "Bio-Inspired Energy-Harvesting Mechanism and Patterns of Dynamic Soaring," Bioinspiration \& Biomimetics, Vol. 12, No. 1, 2017, pp. 1-21.

[11] Fisher, A., Mohamed, A., Elbenhawi, M., Clothier, R., Watkins, S., Carrese, R., Simic, M., Abdulrahim, M., and Palmer, J., "Micro Air Vehicle Soaring in Urban Environments," Australian Control Conference (AuCC), IEEE, New York, 2016, pp. 9-14.

[12] Watkins, S., Mohamed, A., Fisher, A., Clothier, R., Carrese, R., and Fletcher, D., "Towards Autonomous MAV Soaring in Cities: CFD Simulation, EFD Measurement and Flight Trials," International Journal of Micro Air Vehicles, Vol. 7, No. 4, 2015, pp. 441-448. https://doi.org/10.1260/1756-8293.7.4.441

[13] Mohamed, A., Carrese, R., Fletcher, D. F., and Watkins, S., "ScaleResolving Simulations to Predict the Updraught Regions over Buildings for MAV Orographic Lift Soaring," Journal of Wind Engineering and Industrial Aerodynamics, Vol. 140, May 2015, pp. 34-48. https://doi.org/10.1016/j.jweia.2015.01.016

[14] Depenbusch, N., Bird, J., and Langelaan, J., "The AutoSOAR Autonomous Soaring Aircraft, Part 2: Hardware Implementation and Flight Results," Journal of Field Robotics, Vol. 35, No. 4, 2018, pp. 435-458.

[15] Depenbusch, N., Bird, J., and Langelaan, J., "The AutoSOAR Autonomous Soaring Aircraft, Part 1: Autonomy Algorithms," Journal of Field Robotics, Vol. 35, No. 6, 2018, pp. 868-889.

[16] Cybyk, Z., McGrath, E., Frey, M., Drewry, G., Keane, F., and Patnaik, G., "Unsteady Airflows and Their Impact on Small Unmanned Air Systems in Urban Environments," Journal of Aerospace Information Systems, Vol. 11, No. 4, 2014, pp. 178-194.

https://doi.org/10.2514/1.I010000

[17] Mohamed, A., Abdulrahim, M., Watkins, S., and Clothier, R., "Development and Flight Testing of a Turbulence Mitigation System for Micro Air Vehicles," Journal of Field Robotics, Vol. 33, No. 5, 2016, pp. 639-660. https://doi.org/10.1002/rob.2016.33.issue-5

[18] Mohamed, A., Watkins, S., Fischer, A., Marino, M., Massey, K., and Clothier, R., "Bioinspired Wing Surface Pressure Sensing for Attitude Control of Micro Air Vehicles," Journal of Aircraft, Vol. 52, No. 3, 2015, pp. 827-838. https://doi.org/10.2514/1.C032805

[19] Mohamed, A., Watkins, S., Clothier, R., and Abdulrahim, M., "Influence of Turbulence on MAV Roll Perturbations," International Journal of Micro Air Vehicles, Vol. 6, No. 3, 2014, pp. 175-190. https://doi.org/10.1260/1756-8293.6.3.175

[20] Watkins, S., Milbank, J., Loxton, B., and Melbourne, W., "Atmospheric Winds and their Implications for Micro Air Vehicles," AIAA Journal, Vol. 44, No. 11, 2006, pp. 2591-2600. https://doi.org/10.2514/1.22670

[21] Quindlen, F., and Langelaan, J., "Flush Air Data Sensing for SoaringCapable UAVs," AIAA 51st Aerospace Science Meeting, AIAA Paper 2013-1153, 2013, pp. 1-17.

[22] Rasuo, B., Flight Mechanics, Faculty of Mechanical Engineering, Univ. of Belgrade, Belgrade, Serbia, 2014, pp. 40-89 (in Serbian).

[23] Gavrilovic, N., Rasuo, B., Dulikravich, G., and Parezanovic, V., "Commercial Aircraft Performance Improvement Using Winglets," FME Transactions, Vol. 43, No. 1, 2015, pp. 1-8. https://doi.org/10.5937/fmet1501001g 
[24] Gavrilovic, N., Benard, E., Pastor, P., and Moschetta, J., "Performance Improvement of Small Unmanned Aerial Vehicles Through Gust Energy Harvesting," Journal of Aircraft, Vol. 55, No. 2, 2018, pp. 741-754. https://doi.org/10.2514/1.C034531

[25] Gavrilovic, N., Mohamed, A., Marino, M., Watkins, S., Moschetta, J.-M., and Benard, E., "Avian-Inspired Energy-Harvesting from Atmospheric Phenomena for Small UAVs," Bioinspiration \& Biomimetics, Vol. 14, No. 1, 2019, pp. 1-20.

[26] Rasuo, B., "Some Analytical and Numerical Solutions for the Safe Turn Manoeuvres of Agricultural Aircraft: An Overview," Aeronautical Journal, Vol. 111, No. 1123, 2007, pp. 593-599. https://doi.org/10.1017/S000192400000186X

[27] Stojakovic, P., and Rasuo, B., Airplane Flight Dynamics Modeling as Demanded by the Control System Design, Military Technical Inst., Belgrade, Serbia, 2015, pp. 48-96.

[28] Rayleigh, L., "The Soaring of Birds," Nature (London), Vol. 27, No. 701, 1883, pp. 534-535. https://doi.org/10.1038/027534a0

[29] Taylor, K. J., Reynolds, V. K., and Thomas, L. R. A., "Soaring Energetics and Glide Performance in a Moving Atmosphere," Philosophical Transactions, Vol. 371, No. 1704, 2016, pp. 1-14.

[30] Koessler, J., "Dynamic Soaring Kinetic Energy Reference Frames," Journal of Aircraft, Vol. 56, No. 1, 2019, pp. 22-29. https://doi.org/10.2514/1.C034760

[31] Bronz, M., "A Contribution to the Design of Long Endurance Mini Unmanned Aerial Vehicles," Ph.D. Thesis, ISAE-Supaero, Univ. of Toulouse, Toulouse, France, 2012.

[32] Langelaan, J., "A Gust Controller for Small Uninhabited Gliders," Technical Soaring, Vol. 35, No. 2, 2011, pp. 48-60.

[33] Langelaan, J., "Gust Energy Extraction for Mini and Micro Uninhabited Aerial Vehicles," Journal of Guidance, Control, and Dynamics, Vol. 32,
No. 2, 2009, pp. 464-473

https://doi.org/10.2514/1.37735

[34] Kaimal, C., and Finnigan, J., Atmospheric Boundary Layer Flows, Their Structure and Measurements, Oxford Univ. Press, New York, 1994, pp. 32-63, Chap. 2.

[35] Videler, J., Avian Flight, Oxford Ornithology Series, Oxford Univ. Press, New York, 2008, pp. 46-50, Chap. 1.

[36] Scott, D., and McFarland, C., Bird Feathers: A Guide to North American Species, Stackpole Books, Mechanicsburg, PA, 2010, pp. 13-41, Chap. 1.

[37] Brown, R., and Fedde, R., "Airflow Sensors in the Avian Wing," Journal of Experimental Biology, Vol. 179, No. 1, 1993, pp. 13-30.

[38] Gavrilovic, N., Bronz, M., Moschetta, J.-M., and Benard, E., "Bioinspired Wind Field Estimation, Part 1: Angle of Attack Measurements Through Surface Pressure Distribution," International Journal of Micro Air Vehicles, Vol. 10, No. 3, 2018, pp. 273-284. https://doi.org/10.1177/1756829318794172

[39] Wood, T. K., Araujo-Estrada, S., Richardson, T., and Windsor, S., "Distributed Pressure Sensing-Based Flight Control for Small FixedWing Unmanned Aerial Systems," Journal of Aircraft, Vol. 56, No. 5, 2019, pp. 1951-1960. https://doi.org/10.2514/1.C035416

[40] Hattenberger, G., Brnoz, M., and Gorraz, M., "Using the Paparazzi UAV System for Scientific Research," IMAV 2014, International Micro Air Vehicles Conference and Flight Competition, Delft, The Netherlands, Aug. 2014, pp. 247-252.

[41] Lawrance, N., and Sukkarieh, S., "Wind Energy Based Path Planning for a Small Gliding Unmanned Aerial Vehicle," AIAA Guidance, Navigation and Control Conference, AIAA Paper 2009-6112, 2009.

[42] Lawrance, N., and Sukkarieh, S., "Autonomous Exploration of a Wind Field with a Gliding Aircraft," Journal of Guidance, Control, and Dynamics, Vol. 34, No. 3, 2011, pp. 719-733. https://doi.org/10.2514/1.52236 